\title{
In Situ Observations of Phase Transitions in Metastable Nickel (Carbide)/Carbon Nanocomposites
}

Bernhard C. Bayer, ${ }^{*},+\neq$ David A. Bosworth, ${ }^{\S}$ F. Benjamin Michaelis, ${ }^{\dagger}$ Raoul Blume, ${ }^{\|}$Gerlinde Habler, ${ }^{\perp}$ Rainer Abart, ${ }^{\perp}$ Robert S. Weatherup ${ }^{\dagger}$ Piran R. Kidambi, ${ }^{\dagger}$ Jeremy J. Baumberg, ${ }^{\nabla}$ Axel Knop-Gericke, ${ }^{\#}$ Robert Schloegl, ${ }^{\#}$ Carsten Baehtz, ${ }^{\text {IT }}$ Zoe H. Barber, ${ }^{\S}$ Jannik C. Meyer, ${ }^{\ddagger}$ and Stephan Hofmann ${ }^{\dagger}$

${ }^{\dagger}$ Department of Engineering, ${ }^{\S}$ Department of Materials Science and Metallurgy, and ${ }^{\nabla}$ Cavendish Laboratory, University of Cambridge, Cambridge CB2 1TN, United Kingdom

${ }^{\ddagger}$ Faculty of Physics and ${ }^{\perp}$ Department of Lithospheric Research, University of Vienna, 1010 Vienna, Austria

"Helmholtz-Zentrum Berlin für Materialien und Energie, 14109 Berlin, Germany

${ }^{\#}$ Fritz-Haber-Institut der Max-Planck-Gesellschaft, 14195 Berlin, Germany

IIInstitute of Radiation Physics, Helmholtz-Zentrum Dresden-Rossendorf, 01314 Dresden, Germany

Supporting Information

ABSTRACT: Nanocomposite thin films comprised of metastable metal carbides in a carbon matrix have a wide variety of applications ranging from hard coatings to magnetics and energy storage and conversion. While their deposition using nonequilibrium techniques is established, the understanding of the dynamic evolution of such metastable nanocomposites under thermal equilibrium conditions at elevated temperatures during processing and during device operation remains limited. Here, we investigate sputterdeposited nanocomposites of metastable nickel carbide $\left(\mathrm{Ni}_{3} \mathrm{C}\right)$ nanocrystals in an amorphous carbon (a-C) matrix during thermal postdeposition processing via complementary in situ X-ray diffractometry, in situ Raman spectroscopy, and in situ Xray photoelectron spectroscopy. At low annealing temperatures $\left(300{ }^{\circ} \mathrm{C}\right)$ we observe isothermal $\mathrm{Ni}_{3} \mathrm{C}$ decomposition into face-centered-cubic $\mathrm{Ni}$ and amorphous carbon, however, without changes to the initial finely structured nanocomposite morphology. Only for higher temperatures $\left(400-800{ }^{\circ} \mathrm{C}\right)$ Ni-catalyzed isothermal graphitization of the

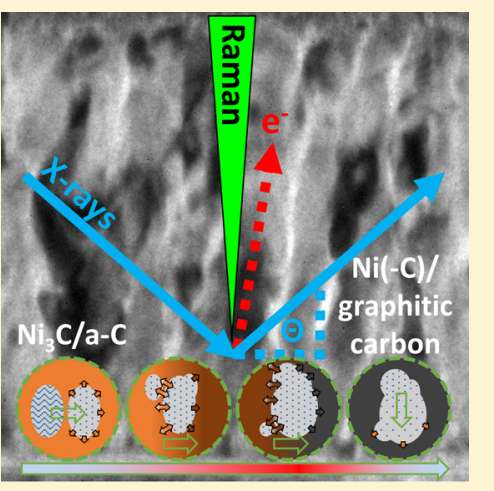
amorphous carbon matrix sets in, which we link to bulk-diffusion-mediated phase separation of the nanocomposite into coarser $\mathrm{Ni}$ and graphite grains. Upon natural cooling, only minimal precipitation of additional carbon from the $\mathrm{Ni}$ is observed, showing that even for highly carbon saturated systems precipitation upon cooling can be kinetically quenched. Our findings demonstrate that phase transformations of the filler and morphology modifications of the nanocomposite can be decoupled, which is advantageous from a manufacturing perspective. Our in situ study also identifies the high carbon content of the Ni filler crystallites at all stages of processing as the key hallmark feature of such metal-carbon nanocomposites that governs their entire thermal evolution. In a wider context, we also discuss our findings with regard to the much debated potential role of metastable $\mathrm{Ni}_{3} \mathrm{C}$ as a catalyst phase in graphene and carbon nanotube growth.

\section{INTRODUCTION}

Nanocomposite $^{1}$ thin films composed of metal and metal carbide nanoparticles in a carbon matrix have a wide application profile ranging from metallurgical hard coatings, ${ }^{2,3}$ magnetics, ${ }^{4,5}$ and sensing, ${ }^{6,7}$ to energy storage and conversion. ${ }^{8-10}$

Substantial efforts in nonequilibrium deposition techniques, ${ }^{11}$ such as sputter deposition, have enabled the controllable fabrication of nanocomposite thin films with thermodynamically metastable filler phases, such as metastable carbides (e.g., $\mathrm{Ni}_{3} \mathrm{C}$ ). ${ }^{6,12-25}$ These metastable filler phases can provide novel functionalities and are hard to obtain in a scalable manner with other deposition techniques. Also bottom-up self-organized nanoscale structuring of filler and matrix phases has been realized. $^{26-30}$

After the initial nonequilibrium deposition, metastable nanocomposite films are however commonly subjected to elevated temperatures during postdeposition treatments, device integration, and operation. The elevated temperatures can thereby enforce thermal equilibrium conditions onto the initially metastable structure of the nanocomposite. An understanding of the dynamic evolution of metastable nanocomposites under thermal equilibrium processing conditions remains however elusive. ${ }^{6,12,13,28,31}$ This is due to only ex situ measurements being available to infer the mechanisms, while direct in situ characterization during the thermally induced phase evolution of the nanocomposites remains largely lacking. Such an understanding is however key to rationally engineer nanocomposites across their entire application spectrum.

Received: February 15, 2016

Revised: September 2, 2016

Published: September 2, 2016 
To address this, we here employ complementary in situ characterization of nanocomposite thin films of nanostructured metastable ${ }^{32-34}$ nickel carbide $\left(\mathrm{Ni}_{3} \mathrm{C}\right)$ nanocrystals in an amorphous carbon (a-C) matrix ${ }^{23}$ during thermal postdeposition processing via a combination of in situ X-ray diffractometry (XRD), in situ Raman spectroscopy, and in situ X-ray photoelectron spectroscopy (XPS). Ni-carbon nanocomposites are chosen as an archetypical model system for filler metals with a medium carbon affinity (i.e., metastable carbide formers), ${ }^{11}$ a class of nanocomposites which further extends to other important materials combinations such as $\mathrm{Co}-$ carbon and $\mathrm{Fe}$-carbon nanocomposites. ${ }^{11,22,31}$ Our complementary in situ characterization thereby yields direct insights into the thermally induced phase evolution and dynamics in such metastable nanocomposite films.

We find that the room temperature deposited $\mathrm{Ni}_{3} \mathrm{C}$ nanocrystals in the a-C matrix isothermally decompose already around $\sim 300{ }^{\circ} \mathrm{C}$ to face-centered-cubic (fcc) Ni nanocrystals, that are saturated with interstitially dissolved carbon (termed $\mathrm{Ni}(-\mathrm{C})$ ), and amorphous carbon, which adds further carbon to the surrounding a-C matrix. In contrast to the low temperature of isothermal $\mathrm{Ni}_{3} \mathrm{C}$ decomposition, we find that significant $\mathrm{Ni}$ catalyzed graphitization of the amorphous carbon matrix during heating ramps and isothermal annealing only sets in at higher temperatures $\left(\sim 400{ }^{\circ} \mathrm{C}\right.$ and above), clearly confirming that $\mathrm{Ni}_{3} \mathrm{C}$ decomposition and $\mathrm{Ni}$-catalyzed graphitization are separate processes. Linked with the Ni-catalyzed graphitization, bulk-diffusion-mediated phase separation into coarse $\mathrm{Ni}$ and graphite grains also occurs only at higher temperatures. Thus, our findings demonstrate that filler phase transformations and nanocomposite morphology modifications can be decoupled, which is highly desirable from a manufacturing point of view. Upon natural cooling of the annealed nanocomposites, only minimal precipitation of deleterious additional carbon from the carbon saturated $\mathrm{Ni}$ crystallites is observed even for high temperature treatments. This implies that even for highly carbon saturated systems precipitation upon cooling can be kinetically quenched. Our findings demonstrate that the high carbon content of the Ni filler crystallites at all stages of processing is a hallmark feature of metal-carbon nanocomposites. Our study provides a framework for the optimization of film microstructure and functionality of metal (carbide)/carbon nanocomposites, which is crucial to their many envisaged applications.

In a wider context, our study also contributes to the elucidation of the recently debated role of $\mathrm{Ni}_{3} \mathrm{C}$ as a possible intermediate bulk catalyst phase in Ni-catalyzed graphene ${ }^{35-44}$ and carbon nanotube $(\mathrm{CNT})^{45-60}$ growth. Taking our $\mathrm{Ni}_{3} \mathrm{C} / \mathrm{a}$ $\mathrm{C}$ nanocomposites as a model system for graphitization from $\mathrm{Ni}_{3} \mathrm{C}$, our in situ derived findings suggest that fcc $\mathrm{Ni}$ with interstitial carbon dissolved $(\mathrm{Ni}(-\mathrm{C}))$, rather than bulk $\mathrm{Ni}_{3} \mathrm{C}$, is the active catalyst phase during graphitic nanostructure growth under typical chemical vapor deposition (CVD) conditions.

\section{METHODS}

We deposit nanocomposite thin films $(\sim 260 \mathrm{~nm}$ film thickness) of metastable $\mathrm{Ni}_{3} \mathrm{C}$ nanoparticles in an a-C matrix in a two target (nickel, carbon) ionized magnetron sputter deposition system. ${ }^{23,61,62}$ No intentional substrate heating is applied, leaving the employed sapphire substrates at temperatures less than $120{ }^{\circ} \mathrm{C}$ (maximum temperature due to plasma heating). To induce deposition of the metastable $\mathrm{Ni}_{3} \mathrm{C}$ phase, a negative bias of $-150 \mathrm{~V}$ is applied to the substrate holder during deposition. ${ }^{23}$ The composition of the films obtained is $\sim 70$ atom \% C and $\sim 30$ atom \% Ni. Following deposition and sample transport in air, the as-deposited $\mathrm{Ni}_{3} \mathrm{C} / \mathrm{a}-\mathrm{C}$ films are subjected to annealing treatments up to $800{ }^{\circ} \mathrm{C}$ in a vacuum $\left(\sim 10^{-5}\right.$ mbar $)$ while concurrently measuring in situ X-ray diffraction (XRD, X-ray wavelength $0.1078 \mathrm{~nm}$ ), in situ Raman spectroscopy (excitation wavelength $532 \mathrm{~nm}$ ), and in situ X-ray photoelectron spectroscopy (XPS). Subsequently samples are left to cool naturally $\left(\sim 100{ }^{\circ} \mathrm{C} / \mathrm{min}\right.$ initial cooling rate $)$ to room temperature (RT). Complementary ex situ characterization is performed using cross-sectional transmission electron microscopy (TEM), selected area electron diffraction (SAED), ${ }^{63}$ and plan-view scanning electron microscopy (SEM) as well as ex situ XRD and Raman spectroscopy. Further details of the experimental methods are included in the Supporting Information.

We note that it is notoriously difficult to assign the carboncontaining $\mathrm{Ni}_{3} \mathrm{C}$ (space group $R \overline{3} \mathrm{c}$ ) with certainty when there is the possibility of the largely isostructural carbon-free hexagonally closed packed (hcp) Ni phase (space group $\mathrm{P6}_{3} /$ $m m c)$ also being present. ${ }^{24,64-66}$ This difficulty arises since both phases consist of an hcp Ni (sub)lattice, which in the case of $\mathrm{Ni}_{3} \mathrm{C}$ has an ordered sublattice of interstitial carbon added. ${ }^{64}$ The additional ordered interstitial carbon does however only slightly change the resulting diffraction patterns, which is why SAED and XRD routinely exhibit difficulties in assigning either phase with certainty. ${ }^{24,64,65}$ This picture is further complicated since recent reports ${ }^{24,64}$ suggested the formation of carboncontaining hcp $\mathrm{Ni}$ (termed hcp $\mathrm{NiC}_{y}$ ) which differs from $\mathrm{Ni}_{3} \mathrm{C}$ only in terms of decreased interstitial carbon ordering; i.e., hcp $\mathrm{NiC}_{y}$ is a disordered form of $\mathrm{Ni}_{3} \mathrm{C}$. We discuss details of our phase assignment to $\mathrm{Ni}_{3} \mathrm{C}$ in the Supporting Information. We note however that our general usage of the terms nickel carbide and $\mathrm{Ni}_{3} \mathrm{C}$ in this study not only includes fully ordered $\mathrm{Ni}_{3} \mathrm{C}$ but also encompasses disordered forms of $\mathrm{Ni}_{3} \mathrm{C}$, approaching the recently suggested ${ }^{24,64}$ hcp $\mathrm{NiC}_{y}$ form (i.e., hcp Ni sublattice including disordered interstitial carbon).

\section{RESULTS}

We start by describing the structure and morphology of the films throughout the thermal processing based on ex situ characterization and then link this to the dedicated in situ experimentation in order to reveal the mechanisms and dynamics of the underlying processes.

Ex Situ Characterization. Figure la shows ex situ TEM bright field images of cross sections of the $\mathrm{Ni}_{3} \mathrm{C} / \mathrm{a}-\mathrm{C}$ films in their as-deposited state, and after annealing at 300 and $800{ }^{\circ} \mathrm{C}$, alongside the corresponding SAED patterns in Figure $1 \mathrm{~b}$. The corresponding plan-view SEM images and Raman spectra are presented in Figure $2 \mathrm{a}$ and $2 \mathrm{~b}$, respectively. The samples were annealed in a vacuum by global heating on a resistive heater.

Figure 1a shows that the as-deposited films exhibit a columnar grain structure with dark contrast grains that are elongated perpendicular to the substrate surface (average grain sizes: long axis perpendicular to substrate surface, $88 \pm 44 \mathrm{~nm}$; short axis parallel to substrate surface, $20 \pm 8 \mathrm{~nm}$ ) and that are embedded in a matrix of lighter contrast, which is finely dispersed between the dark contrast grains. On the basis of the SAED, we identify the dark contrast grains as $\mathrm{Ni}_{3} \mathrm{C}$ (reflections indexed in Figure 1b, see also Supporting Information for discussion of $\mathrm{Ni}_{3} \mathrm{C}$ assignment $)^{24,64-66}$ and the finely dispersed light contrast matrix as a-C (based on the absence of a strong graphitic reflection in the SAED in Figure $1 b$ ). The top surface 


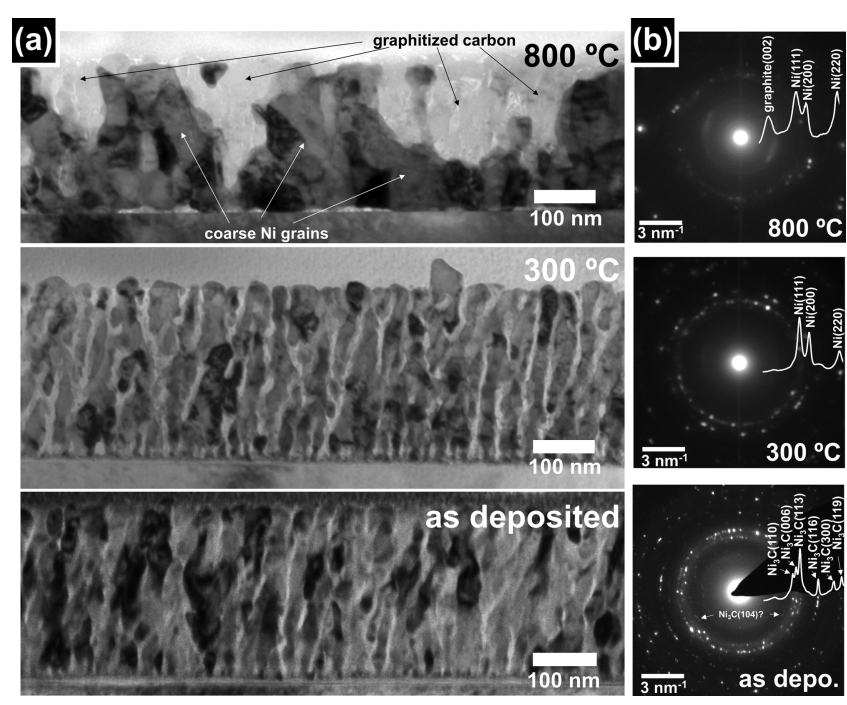

Figure 1. (a) Cross-sectional bright field TEM micrographs of Nicarbon nanocomposites in as-deposited state (bottom) and after anneals at 300 (middle) and $800{ }^{\circ} \mathrm{C}$ (top). (b) SAED patterns corresponding to (a). The overlays show extracted radially integrated SAED profiles ${ }^{63}$ with the identified phases indexed. Note that in the SAED pattern of the as-deposited film additional possible $\mathrm{Ni}_{3} \mathrm{C}(104)$ reflections $^{24,64,65}$ are indicated (see Supporting Information for a comment on $\mathrm{Ni}_{3} \mathrm{C}$ phase assignment). Estimated uncertainty in temperature for the ex situ anneals is $\pm 10{ }^{\circ} \mathrm{C}$.
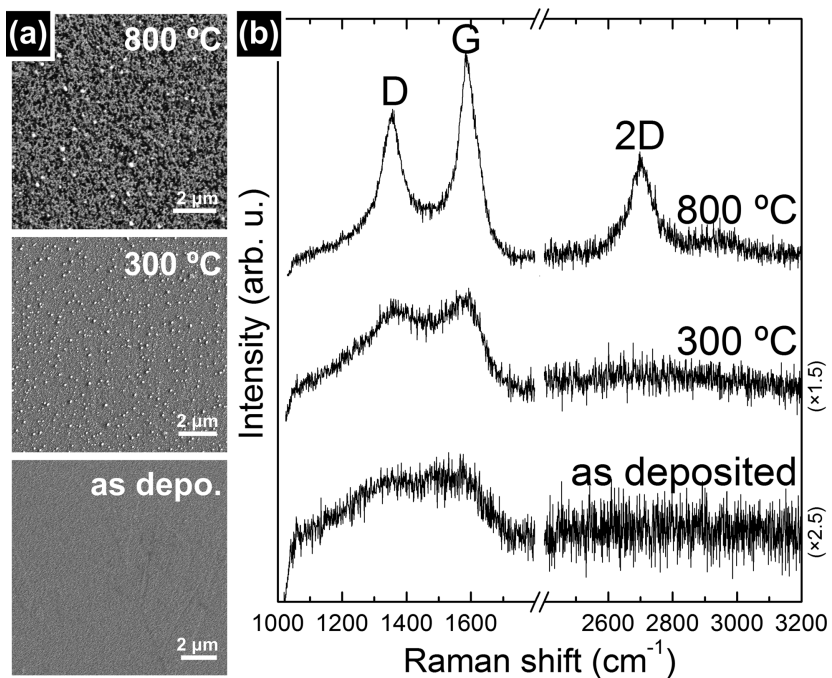

Figure 2. (a) SEM micrographs (plan view) of the Ni-carbon nanocomposite surface in as-deposited state (bottom) and after anneals at 300 (middle) and $800{ }^{\circ} \mathrm{C}$ (top), corresponding to Figure 1. (b) Ex situ Raman spectra of $\mathrm{Ni}$-carbon nanocomposites in asdeposited state (bottom) and after anneals at 300 (middle) and 800 ${ }^{\circ} \mathrm{C}$ (top), corresponding to (a) and Figure 1. The intensities of the asdeposited and $300{ }^{\circ} \mathrm{C}$ spectra have been multiplied by the indicated values to improve readability.

of the as-deposited films appears smooth in the TEM cross section which aligns well with the largely featureless SEM image in plan view (Figure 2a). In keeping with our indirect SAED assignment of the matrix to a-C, the Raman spectrum in Figure $2 \mathrm{~b}$ shows a very low intensity peak representing a merged $\mathrm{D}$ and $\mathrm{G}$ band and no signal in the $2 \mathrm{D}$ region, both indicative of highly disordered carbon. ${ }^{67}$
Upon annealing at $300{ }^{\circ} \mathrm{C}$ and subsequent cooling in the vacuum the cross-sectional grain structure of columnar metalcontaining grains in a finely dispersed amorphous carbon matrix is preserved (Figure 1a). Only some increase in the average dark contrast grain size perpendicular to the substrate occurs (long axis perpendicular to substrate, $105 \pm 63 \mathrm{~nm}$; short axis parallel to substrate, $29 \pm 10 \mathrm{~nm}$ ), indicating that dark contrast grains start to merge in the direction perpendicular to the substrate. Likewise, only very limited roughening of the film surface (Figure 2a) is observed. While the overall change in film morphology is limited, the corresponding SAED pattern indicates a drastic change in the dark contrast Ni-containing phase from $\mathrm{Ni}_{3} \mathrm{C}$ to fcc Ni (Figure 1b). Concurrently, we find only a small increase in the carbon ordering, indicated by the only small increase in overall Raman intensity and the still strongly overlapping $\mathrm{D}$ and $\mathrm{G}$ peaks as well as the lack of a $2 \mathrm{D}$ peak (Figure $2 \mathrm{~b}$ ) ${ }^{20,67}$ Correspondingly, in the SAED (Figure 1b) a pronounced graphitic peak remains absent for the $300{ }^{\circ} \mathrm{C}$ annealed films, confirming a still largely amorphous carbon matrix.

Further annealing at $800{ }^{\circ} \mathrm{C}$ (and subsequent cooling) leads to a drastic change in film morphology. TEM (Figure 1a) and SAED (Figure $1 \mathrm{~b}$ ) show that pronounced phase separation into coarse and more isotropically shaped dark contrast metallic fcc $\mathrm{Ni}$ grains (isometric grain size, $83 \pm 42 \mathrm{~nm}$ ) and coarse carbon grains (isometric grain size, $60 \pm 33 \mathrm{~nm}$ ) occurs. The asdeposited columnar grain structure of fine-grained metallic filler and interdispersed a-C matrix is thereby destroyed. The appearance of a strong graphitic reflection in SAED (Figure $1 \mathrm{~b}$ ) indicates that significant ordering of the carbon toward a graphitic structure has occurred. A graphitic interlayer distance of $\sim 0.35 \mathrm{~nm}$ is estimated from the SAED pattern, which is consistent with nanocrystalline graphite with partly turbostratic layer stacking. From the cross-sectional TEM we further find that graphitic domains form largely toward the top surface of the film. This corresponds well with the dark contrast patches apparent in SEM which we ascribe to graphitic grains (Figure $2 \mathrm{a})$. The graphitization is also well reflected in the corresponding Raman spectrum (Figure $2 b$ ) which for the $800{ }^{\circ} \mathrm{C}$ sample shows intense and well-separated D and G peaks, as well as the appearance of a $2 \mathrm{D}$ signal. This confirms the formation of nanocrystalline graphite, ${ }^{31,67,68}$ where we estimate from the ratio of the $D$ to $G$ peak intensities a lower bound for the in-plane-ordering size of $\sim 6.5 \mathrm{~nm} .{ }^{67}$ The drastic change in structure and morphology of the nanocomposite indicates that significant bulk diffusion has occurred in the $\mathrm{Ni}-$ carbon system during the high temperature annealing.

Our ex situ observations so far indicate three major processes that occur upon the heat treatments: (1) At $300{ }^{\circ} \mathrm{C}$ the filler phase transforms from $\mathrm{Ni}_{3} \mathrm{C}$ to fcc $\mathrm{Ni}$. (2) At annealing temperatures greater than $300{ }^{\circ} \mathrm{C}$ the graphitization of a-C to nanocrystalline graphite sets in. (3) $\mathrm{Ni}$ grain growth and thus destruction of the fine-grained nanocomposite morphology occurs. While graphitization and $\mathrm{Ni}$ grain growth appear linked, the $\mathrm{Ni}_{3} \mathrm{C}$ decomposition (to fcc $\mathrm{Ni}$ and a-C) at $300{ }^{\circ} \mathrm{C}$ did not influence the fine-grained morphology of the as-deposited nanocomposite. This indicates that phase transformations and film morphology modifications can be decoupled in such nanocomposite systems.

The ex situ characterization in Figures 1 and 2 is however limited to the "cold" postprocessing state of the nanocomposites, and thus cannot directly elucidate the state of the material while the phase transformations and morphology 
changes are actually occurring at elevated temperature. Therefore, important aspects such as whether the phase transformations proceed during heating ramps, isothermally at temperature, or are a result of subsequent cooling remain unknown. ${ }^{6,69-75}$ Also, ex situ characterization can only indirectly imply the temperature regimes and time scales over which the observed processes proceed. To reveal such dynamics, we now link our ex situ observations above to dedicated in situ characterization.

In Situ XRD. We first investigate the structural evolution of the $\mathrm{Ni}_{3} \mathrm{C} / \mathrm{a}-\mathrm{C}$ nanocomposites using a previously described in situ XRD system, ${ }^{76-79}$ in which the $\mathrm{Ni}_{3} \mathrm{C} / \mathrm{a}-\mathrm{C}$ nanocomposite samples are globally heated by a resistive heater (as in our ex situ annealing above). Figure 3a shows a series of in situ X-ray diffractograms acquired at salient stages during the vacuum annealing of an as-deposited $\mathrm{Ni}_{3} \mathrm{C} / \mathrm{a}-\mathrm{C}$ nanocomposite. As deposited we find a diffraction pattern corresponding to essentially phase pure $\mathrm{Ni}_{3} \mathrm{C}$ (see also Supporting Information for a comment on assignment/definition of $\mathrm{Ni}_{3} \mathrm{C}$ ). ${ }^{24,64-66}$ With heating this pattern transforms to show the reflections of fcc Ni. We extract the corresponding phase fractions of $\mathrm{Ni}_{3} \mathrm{C}$ and $\mathrm{fcc}$ $\mathrm{Ni}$ by Rietveld refinement and plot the evolution of the phase fraction in Figure 3b. In agreement with our ex situ observations above, we find the onset of the $\mathrm{Ni}_{3} \mathrm{C} \rightarrow$ fcc Ni transformation at $300{ }^{\circ} \mathrm{C}$. The inset in Figure $3 \mathrm{~b}$ shows how this phase transformation proceeds with time, indicating a phase transformation from $\mathrm{Ni}_{3} \mathrm{C}$ to fcc $\mathrm{Ni}$ over a time scale of tens of minutes at $300{ }^{\circ} \mathrm{C}$. Upon further annealing to temperatures higher than $300{ }^{\circ} \mathrm{C}$ and up to $800{ }^{\circ} \mathrm{C}$, the fcc $\mathrm{Ni}$ remains the only observed phase. Also after natural cooling from $800{ }^{\circ} \mathrm{C}$ to room temperature, fcc $\mathrm{Ni}$ remains the only detected phase. After cooling we find from Rietveld refinement that the fcc Ni lattice constant is $0.35255 \pm 0.00005 \mathrm{~nm}$, which corresponds ${ }^{32}$ to a carbon content of $0.19 \pm 0.07$ atom $\%$ in the Ni. This carbon content is significantly higher than the equilibrium carbon content expected for $\mathrm{Ni}$ at room temperature of $<0.01$ atom $\%^{32,80}$ and instead corresponds to the expected equilibrium carbon content in $\mathrm{Ni}$ for temperatures between 580 and $690{ }^{\circ} \mathrm{C} .{ }^{80}$ This observation thus indicates that the cooled fcc $\mathrm{Ni}$ particles still contain a relatively large amount of carbon interstitially dissolved within them; i.e., the $\mathrm{Ni}$ particles are a solid solution of carbon interstitially dissolved in fcc Ni (here termed $\mathrm{Ni}(-\mathrm{C})$ ).

We note that we do not observe the appearance of any Bragg peak associated with graphite in the XRD data (neither during annealing nor upon natural cooling). In contrast, for the same processing temperatures the ex situ analysis clearly shows the formation of nanocrystalline graphitic grains via SAED (Figure 1b) and Raman spectroscopy (Figure 2b). SAED and Raman spectroscopy are known to be more sensitive toward the presence of smaller ordered graphitic regions compared to $\mathrm{XRD}$, which is only sensitive to larger ordered regions. ${ }^{6,81}$ Therefore, the lack of a graphitic signal in XRD ("XRDamorphous" structure of carbon matrix; also confirmed by ex situ XRD of the same ex situ $800{ }^{\circ} \mathrm{C}$ annealed sample from Figures 1 and 2) reaffirms that the carbon matrix is composed of small nanometer-sized grains even after $800{ }^{\circ} \mathrm{C}$ annealing. Due to this XRD-amorphous nature of the nanocrystalline graphite, our in situ XRD measurements cannot, however, answer the important question of whether the formation of the nanocrystalline graphite occurs during the initial heating ramp, isothermally, or upon cooling. All these scenarios have been previously suggested in the literature as possible graphite
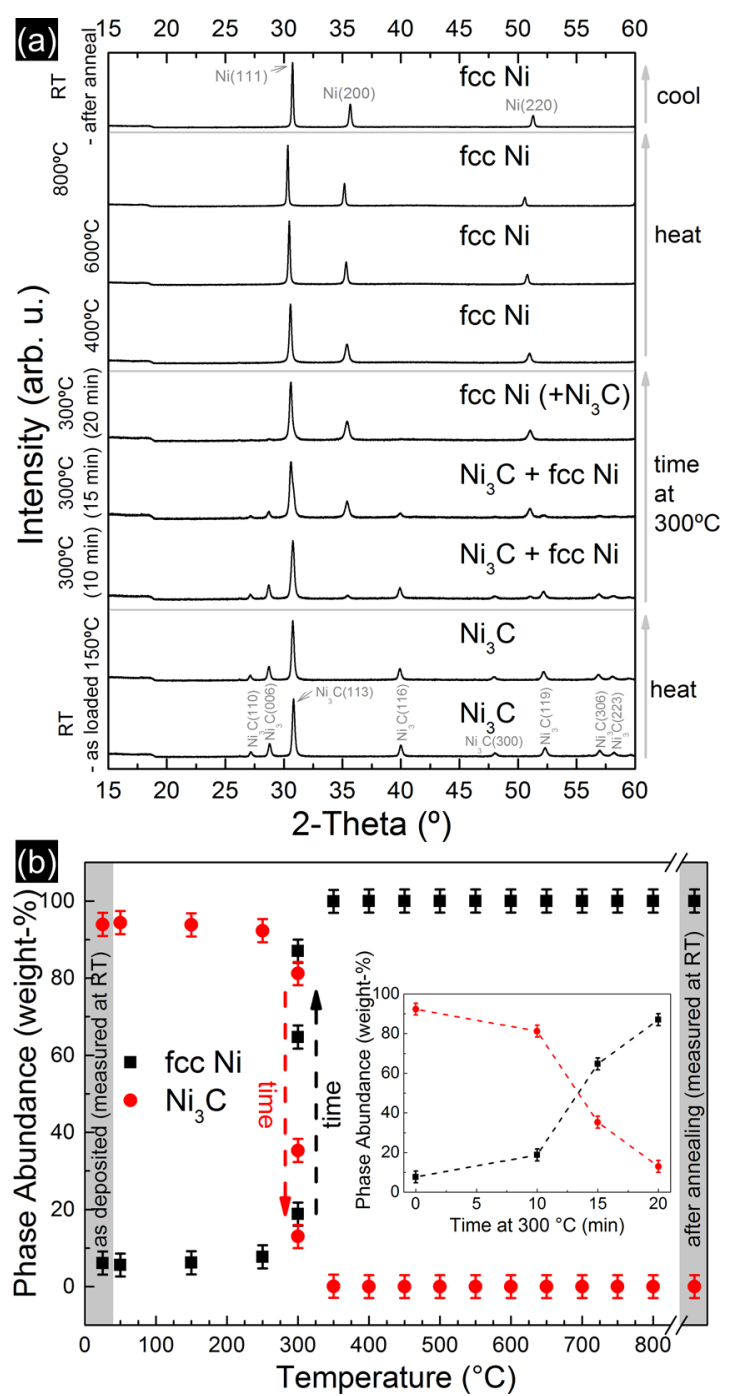

Figure 3. (a) In situ XRD patterns (X-ray wavelength $0.1078 \mathrm{~nm}$ ) showing temperature and time-resolved evolution of the structure of the $\mathrm{Ni}$-carbon nanocomposites (from bottom to top). The step at $\sim 18^{\circ}$ is related to the arrangement of detector and X-ray entrance/exit slits into the reaction chamber. The small peak at $26.2^{\circ}$ is related to the sapphire substrate. We note that reflection positions shift throughout temperature dependent scans due to thermal expansion. (b) Phase abundance of $\mathrm{Ni}_{3} \mathrm{C}$ and $\mathrm{fcc} \mathrm{Ni}$ as a function of annealing temperature, extracted from the in situ data in (a) via Rietveld refinement. Only $\mathrm{Ni}$ and $\mathrm{Ni}_{3} \mathrm{C}$ were included in the abundance quantification, while graphite was not detectable in the XRD data (see main text) and therefore not included in the abundance estimation. The inset shows the evolution of the phase abundance of $\mathrm{Ni}_{3} \mathrm{C}$ and fcc $\mathrm{Ni}$ as a function of annealing time at $300{ }^{\circ} \mathrm{C}$. Note that based on qualitative phase identification fcc $\mathrm{Ni}$ is absent for as-deposited films and annealed films up to $250^{\circ} \mathrm{C}$. As an upper bound of fcc Ni content that could be "hidden" in the signal noise, quantitative Rietveld refinement indicates a maximum of $<7 \mathrm{wt} \%$. Estimated uncertainty in temperature for the in situ XRD measurements is $\pm 40{ }^{\circ} \mathrm{C}$.

formation pathways for $\mathrm{Ni}-$ carbon systems. ${ }^{6,69-75}$ To clarify this point, we now turn to in situ Raman spectroscopy in Figure 4, which provides higher sensitivity toward smaller scale carbon ordering during the thermal processing.

In Situ Raman Spectroscopy. We use a previously described in situ Raman spectroscopy setup ${ }^{82,83}$ in which the Raman probe laser (532 $\mathrm{nm}$ ) is simultaneously used for highly localized sample heating and sensing (optical spot size $\sim 1 \mu \mathrm{m}$ ). 


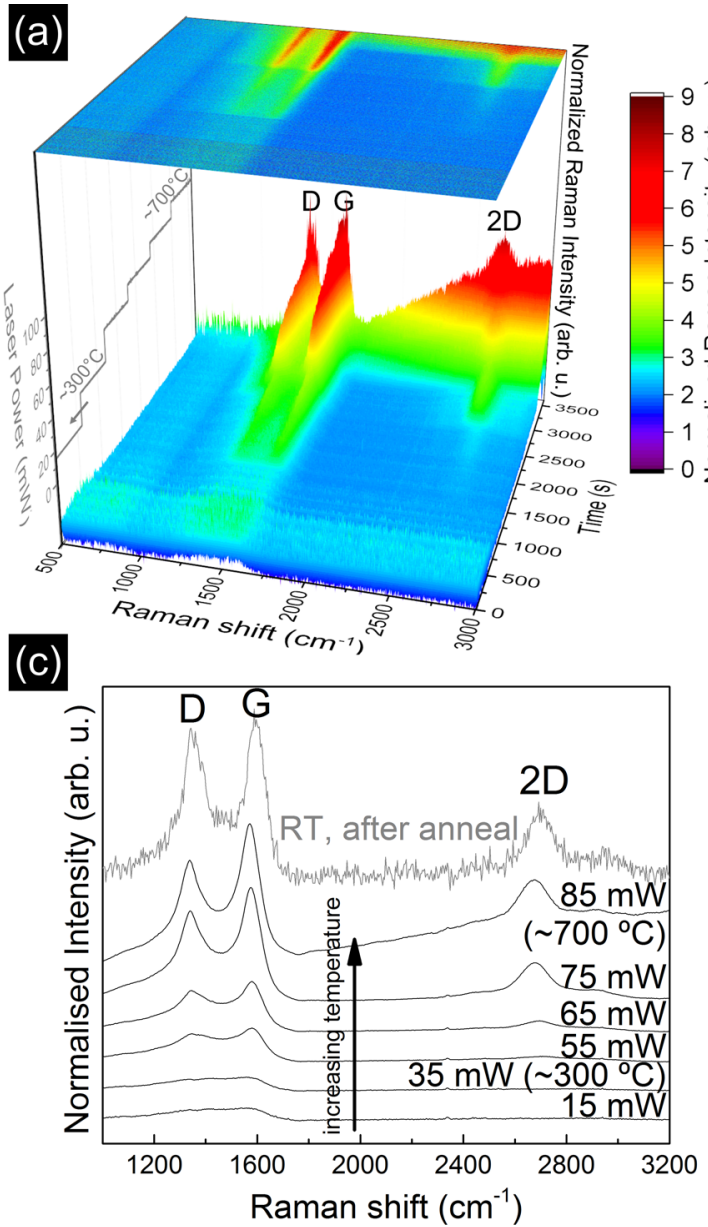

(b)
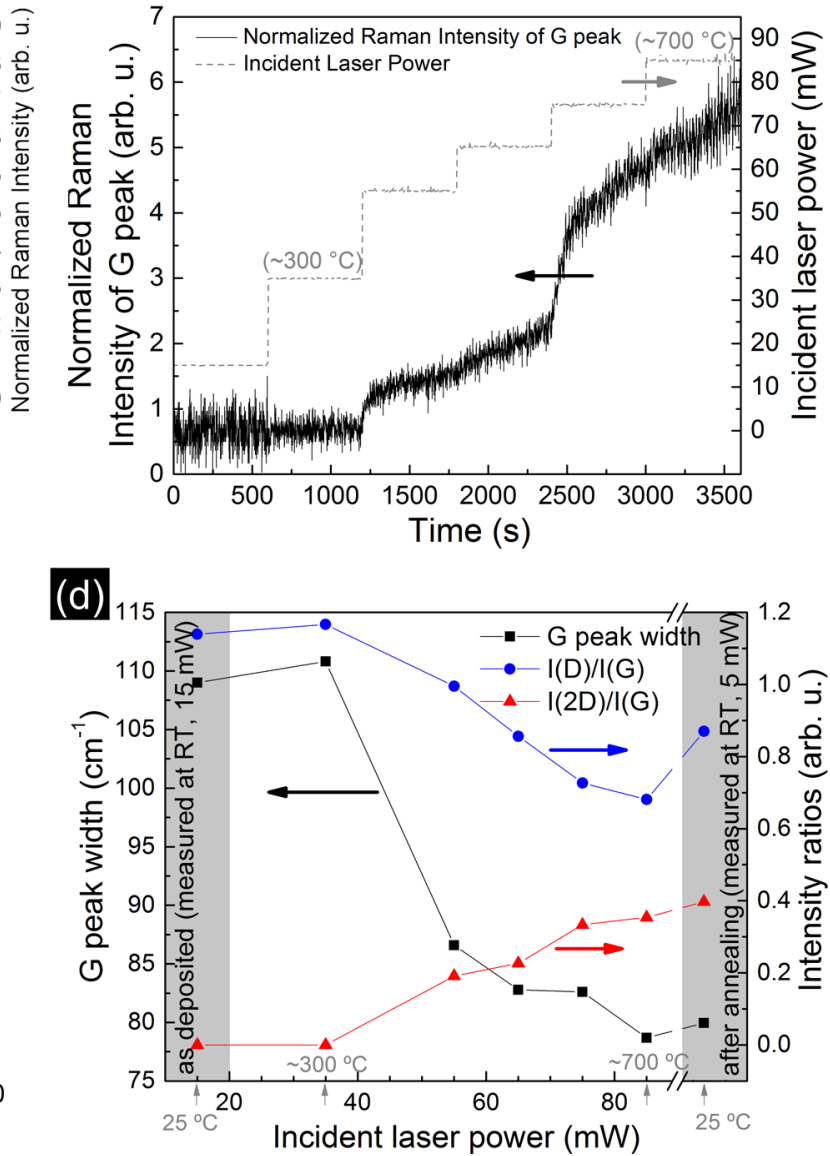

Figure 4. (a) Typical in situ Raman spectroscopy data set showing the evolution of the carbon-related Raman bands as a function of stepwise increases in incident laser power (normalized Raman intensity false-colored surface map with $x$-axis showing Raman shift, $y$-axis showing time, and $z$ axis showing normalized Raman intensity; an additional false-colored surface projection of normalized Raman intensity is projected onto the $x y$-plane [top of graph]; the $y z$-plane shows the stepwise increased incident laser power as a function of time). (b) Time evolution of the normalized G peak intensity (extracted from (a)) as a function of the stepwise increases in incident laser power. (c) Time-averaged Raman spectra as a function of applied laser power. Averaging was performed over the time-resolved Raman spectra in (a) at constant incident laser power steps. Spectra are offset for clarity. (d) G peak width and $I(\mathrm{D}) / I(\mathrm{G})$ and $I(2 \mathrm{D}) / I(\mathrm{G})$ intensity ratios as a function of applied laser power, extracted from the Raman spectra in (c). For a comment on temperature estimations, see the Supporting Information. Estimated uncertainty in temperature for the in situ Raman measurements is $\pm 50^{\circ} \mathrm{C}$.

Figure 4a shows the data from a typical in situ experiment where the laser power is increased stepwise while measuring time-resolved Raman spectra at a fixed position on the Nicarbon nanocomposite film. Note that in this setup with increasing laser power not only the temperature of the sampled area but also the intensity of the acquired Raman spectra increases. In order to remove this influence of increasing signal intensity related to increased laser power, only the normalized Raman intensity is plotted here, where the measured Raman raw intensity has been divided by the incident laser power.

We estimate the local temperature from the in situ laser heating via calibration against ex situ annealed samples (see Supporting Information): For a laser power of $15 \mathrm{~mW}$, heating of the sample is found to be negligible. Temperatures of $\sim 300$ ${ }^{\circ} \mathrm{C}$ for $35 \mathrm{~mW}$ and of $\sim 700{ }^{\circ} \mathrm{C}$ for $85 \mathrm{~mW}$ are estimated, respectively, with a linear relationship between temperature and applied laser power. ${ }^{83,84}$ We note that at higher laser powers of $>75 \mathrm{~mW}$ the background in the spectra also develops a contribution due to thermal blackbody radiation, ${ }^{85}$ although we find that the blackbody signal is insufficient in intensity to reliably estimate local temperatures from it.
Figure 4a shows that, in agreement with our ex situ data, the as-deposited nanocomposite film initially shows a low intensity, merged $\mathrm{D}$ and $\mathrm{G}$ band and no $2 \mathrm{D}$ signal, consistent with the initially present a-C. ${ }^{67}$ When increasing the laser power (and thus local heating temperature) we find that gradually the $\mathrm{D}$ and $G$ bands become more intense and narrower and their overlap reduces. Concurrently, a $2 \mathrm{D}$ signal emerges (starting at $55 \mathrm{~mW}$ ). This is consistent with graphitization in the sample from a-C toward nanocrystalline graphite. ${ }^{67}$

To quantify the temporal dynamics of this process, Figure $4 \mathrm{~b}$ follows the time evolution of the $G$ peak intensity $(I(G))$ as a function of the stepwise increases in laser heating. For laser powers of up to $35 \mathrm{~mW}\left(\sim 300{ }^{\circ} \mathrm{C}\right)$ we find a roughly constant $I(\mathrm{G})$ with time. This confirms that graphitic ordering for anneals up to $300{ }^{\circ} \mathrm{C}$ is minor. Increasing the laser power from 35 to $55 \mathrm{~mW}$ (corresponding to $\sim 470{ }^{\circ} \mathrm{C}$ ) results in an immediate sharp increase in $I(G)$ followed by a continuous gradual increase in $I(G)$ with time. These observations imply that graphitization occurs during the initial rapid heating ramp and then further continues isothermally. We find similarly sharp increases in $I(G)$ with stepwise laser power increases, followed 
by a gradual increase in $I(G)$ with time, also for other power steps up to $85 \mathrm{~mW}$. The variation in magnitude of these sharp $I(G)$ increases for different laser powers may relate to the $\mathrm{Ni}-$ carbon system crossing activation energy thresholds during particular power steps (e.g., the step from $35\left(\sim 300^{\circ} \mathrm{C}\right)$ to 55 $\mathrm{mW}\left(\sim 470{ }^{\circ} \mathrm{C}\right)$ may be related to a completed transition from $\mathrm{Ni}_{3} \mathrm{C}$ to fcc $\mathrm{Ni}$ ). We emphasize that (unlike the ex situ measurements above) these Raman measurements are taken in situ on the hot sample, i.e. without any intermediate cooling. Therefore, the observed evolution of the Raman signature from a-C toward nanocrystalline graphite during annealing clearly confirms that in these nanocomposites graphitization occurs during heating ramps and isothermal annealing, rather than solely by precipitation on cooling.

Figure $4 \mathrm{c}$ plots time-averaged spectra for each laser power (i.e., averaging over the isothermal increase in signal), which improves the signal-to-noise ratio. Extracted from these averaged spectra, we quantify the $G$ peak width, and the intensity ratios of $I(D) / I(G)$ and $I(2 D) / I(G)$ as a function of incident laser power in Figure 4d. This confirms that with increasing temperature the $G$ peak generally narrows and the $I(2 \mathrm{D}) / I(\mathrm{G})$ ratio increases while the $I(\mathrm{D}) / I(\mathrm{G})$ ratio concurrently decreases, again consistent with graphitization from a-C toward nanocrystalline graphite. ${ }^{67}$

Upon cooling (i.e., after the laser power is reduced from 85 to $5 \mathrm{~mW})$ we find an only a minor increase $(<10 \%)$ in the $\mathrm{G}$ peak normalized intensity $I(G)$ as well as an increase in the $I(\mathrm{D}) / I(\mathrm{G})$ ratio. This indicates that at most only a small amount of disordered carbon can have precipitated out of the $\mathrm{Ni}$ particles upon cooling, directed toward the buried Ni filler/ carbon matrix interface and/or toward the sample surface. To further elucidate such changes on the nanocomposite's (sub)surface, we finally employ in situ XPS.

In Situ XPS. XPS provides (sub)surface sensitive chemical information (total information depth at the applied excitation energy is estimated to $\sim 3.6 \mathrm{~nm}$ ), which is complementary to the "bulk"-sensitive XRD (estimated information depth of $\sim 200 \mathrm{~nm}$ ) and Raman spectroscopy (information depth for such nanocomposite films typically estimated at $\sim 100 \mathrm{~nm}^{81}$ ). Figure 5 shows in situ XP spectra of the $\mathrm{C} 1 \mathrm{~s}$ (Figure 5a) and $\mathrm{Ni} 2 \mathrm{p}$ (Figure $5 \mathrm{~b}$ ) core level evolution of a $\mathrm{Ni}_{3} \mathrm{C} / \mathrm{a}-\mathrm{C}$ nanocomposite film during salient stages of vacuum annealing, where global back-side heating is used in the in situ XPS chamber, ${ }^{86,87}$ similar to our ex situ preparations and the in situ XRD. We first assign the observed XPS peaks based on comparison to literature (see also Supporting Information Table 1) before describing the observed evolution of surface chemistry upon annealing.

The C 1s spectrum of the as-loaded film (i.e., as-deposited film after air exposure prior to XPS measurements) has a majority component at a binding energy (BE) of $284.9 \mathrm{eV}$, which we assign to disordered carbon (with a certain fraction of $\mathrm{sp}^{3}$-like bonding $)^{88,89}$ followed by a lower intensity component at $284.4 \mathrm{eV}$ which we attribute to $\mathrm{sp}^{2}$ bonded carbon. ${ }^{88,89} \mathrm{~A}$ minor component is at $283.7 \mathrm{eV}$, which has been previously ascribed to a solid solution of carbon interstitially dissolved in metallic $\mathrm{Ni}^{88}$ (here termed $\mathrm{Ni}(-\mathrm{C})$, where the comparably high $\mathrm{BE}$ indicates significant carbon dissolution) but also to $\mathrm{Ni}_{3} \mathrm{C}$. The reported $\mathrm{BEs}$ of $\mathrm{Ni}_{3} \mathrm{C}$ however vary in the literature: Notably another minority component in our $\mathrm{C} 1 \mathrm{~s}$ data lies at a very low $\mathrm{BE}$ of $283.0 \mathrm{eV}$, which also has been previously assigned to crystalline $\mathrm{Ni}_{3} \mathrm{C}$. ${ }^{19}$ (We note that the monolayer thin carbide $\mathrm{Ni}_{2} \mathrm{C}$ surface reconstruction on $\mathrm{Ni}(111)$ has also

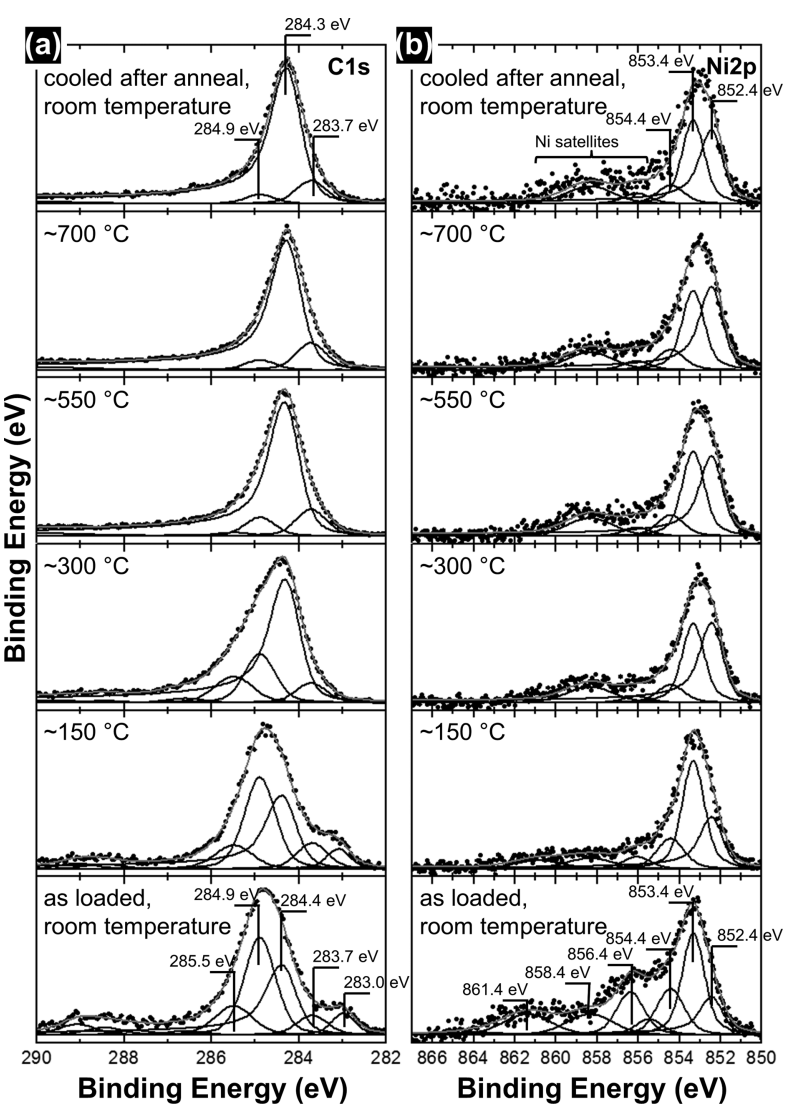

Figure 5. In situ XP spectra of the (a) C 1s and (b) Ni 2p regions as a function of vacuum annealing temperature (from bottom to top). Estimated uncertainty in temperature for the in situ XPS measurements is $\pm 40{ }^{\circ} \mathrm{C}$.

been reported but at a slightly higher binding energy of 283.2 $\mathrm{eV} .^{91}$ ) We find that the presence of this low energy peak at $283.0 \mathrm{eV}$ correlates well with the presence of crystalline $\mathrm{Ni}_{3} \mathrm{C}$ signatures in TEM/SAED and XRD data of our as-deposited films and upon heating (see below). At higher BEs one further $\mathrm{C} 1 \mathrm{~s}$ minority component in the as-deposited films is located at $285.5 \mathrm{eV}$, which is a signature of adventitious carbon adsorbates from sample storage in ambient air. ${ }^{92,93}$

The corresponding $\mathrm{Ni} 2 \mathrm{p}$ spectrum of the as-loaded film shows peaks corresponding to an oxidized $\mathrm{Ni}$ surface (minor component at $854.4 \mathrm{eV}$ and peaks with $\mathrm{BE}>855 \mathrm{eV}$ in $\mathrm{Ni}$ $2 \mathrm{p}),{ }^{94}$ which is consistent with the sample having been stored in ambient air prior to loading into the in situ XPS system. ${ }^{19}$ The nonoxide majority $\mathrm{Ni} 2 \mathrm{p}$ component in the as-loaded films is at $853.4 \mathrm{eV}$, which is close to literature assignments of $\mathrm{Ni}$ with carbon interstitially dissolved $(\mathrm{Ni}(-\mathrm{C}))^{88}$ but is also consistent with previously reported $\mathrm{BEs}$ for $\mathrm{Ni}_{3} \mathrm{C}$. ${ }^{21,22,90}$ Another smaller Ni $2 p$ component in the as-loaded sample is at $852.4 \mathrm{eV}$, which is commonly attributed to metallic $\mathrm{Ni}^{88}$

Based on our assignments, we conclude that the as-loaded sample surface exhibits signs of $\mathrm{Ni}_{3} \mathrm{C}$ (C 1s, $283.0 \mathrm{eV}$, and/or $283.7 \mathrm{eV} / \mathrm{Ni} 2 \mathrm{p}, 853.4 \mathrm{eV}$ ) and a substoichiometric $\mathrm{Ni}(-\mathrm{C})$ solid solution $(283.7 \mathrm{eV} / 853.4 \mathrm{eV})$. A combination of these $\mathrm{C}$ 1s signatures is commonly found for XP spectra of $\mathrm{Ni}_{3} \mathrm{C} / \mathrm{a}-\mathrm{C}$ nanocomposites, even when only $\mathrm{Ni}_{3} \mathrm{C}$ crystals are observed in TEM/SAED or XRD (as is also the case here).${ }^{19}$ A mixture of disordered $\mathrm{sp}^{3}$-like $(284.9 \mathrm{eV})$ and $\mathrm{sp}^{2}(284.4 \mathrm{eV})$ carbon is further found in the as-loaded samples, which is consistent with the a-C matrix observed in TEM/SAED and Raman spectros- 


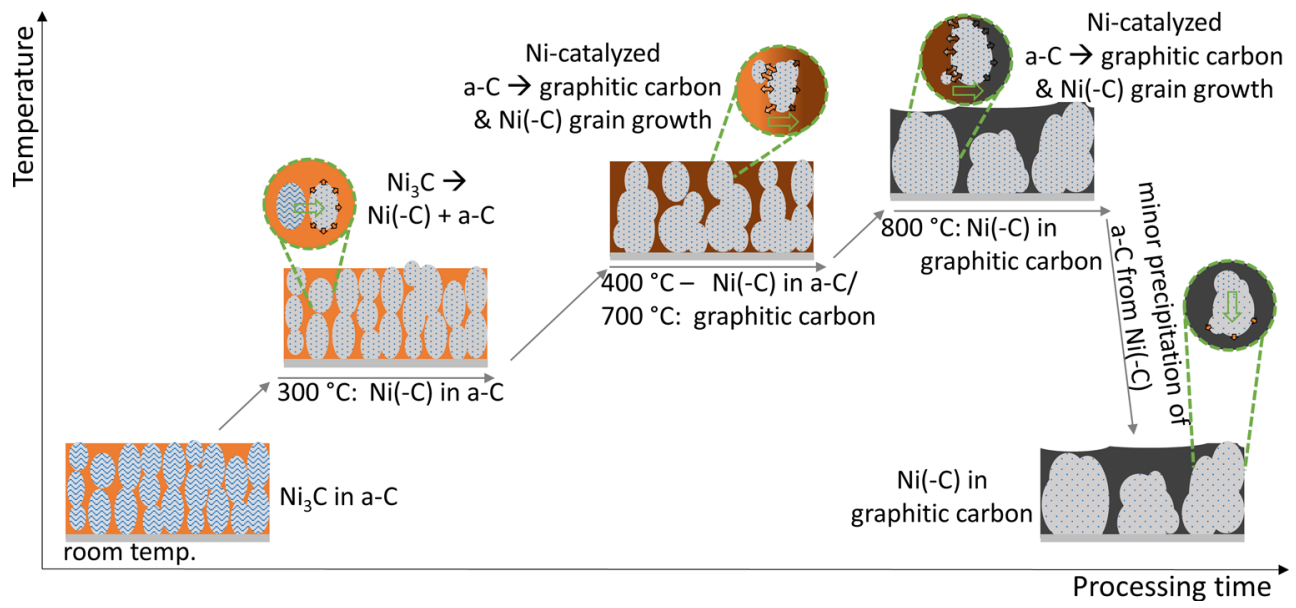

Figure 6. Schematic sketch illustrating the morphological and structural evolution of the Ni-carbon nanocomposites during thermal annealing, as derived from our in situ study.

copy. The as-loaded spectra further indicate that upon sample storage in air surface oxidation has occurred. This presumably proceeds via the decomposition of an initially present $\mathrm{Ni}_{3} \mathrm{C}$ surface, resulting in an mixture of some oxidized $\mathrm{Ni}(854.4 \mathrm{eV}$ and $>855 \mathrm{eV})$, some metallic $\mathrm{Ni}(852.4 \mathrm{eV})$, and some of the observed a-C. ${ }^{95}$ Adventitious carbon adsorption $(285.5 \mathrm{eV})$ onto the sample surface from storage in ambient air further complicates the surface chemistry in the as-loaded sample.

We now turn to the thermal evolution of the surface chemistry upon vacuum annealing: When heating to $150{ }^{\circ} \mathrm{C}$, the $\mathrm{Ni}$ oxides reduce (decrease of $854.4 \mathrm{eV}$ and $>855 \mathrm{eV}$ components) and a corresponding small increase in metallic $\mathrm{Ni}$ is observed $(852.4 \mathrm{eV})$. The $\mathrm{Ni} 2 \mathrm{p}$ now predominantly shows the presence of $\mathrm{Ni}_{3} \mathrm{C} / \mathrm{Ni}(-\mathrm{C})(853.4 \mathrm{eV})$ accompanied by a small amount of metallic $\mathrm{Ni}(852.4 \mathrm{eV})$. The $\mathrm{C} 1 \mathrm{~s}$ signatures do not show significant changes when heating from room temperature to $150{ }^{\circ} \mathrm{C}$.

Increasing the annealing temperature further to $300{ }^{\circ} \mathrm{C}$ (which is the $\mathrm{Ni}_{3} \mathrm{C}$ decomposition temperature estimated from in situ XRD and TEM above) leads however to a drastic change in both the $\mathrm{Ni} 2 \mathrm{p}$ and $\mathrm{C}$ 1s signatures: The $\mathrm{Ni}_{3} \mathrm{C} / \mathrm{Ni}(-\mathrm{C})$ component in the $\mathrm{Ni} 2 \mathrm{p}(853.4 \mathrm{eV})$ significantly reduces in relative intensity (but does not vanish), while the metallic $\mathrm{Ni}$ component $(852.4 \mathrm{eV})$ increases, yielding now roughly a $1: 1$ ratio of $\mathrm{Ni}_{3} \mathrm{C} / \mathrm{Ni}(-\mathrm{C})$ and metallic $\mathrm{Ni}$ intensities. Importantly, the $283.0 \mathrm{eV}$ component in the $\mathrm{C} 1 \mathrm{~s}$ concurrently disappears, suggesting that $\mathrm{Ni}_{3} \mathrm{C}$ decomposes. The in situ XPS data therefore corroborates isothermal decomposition of $\mathrm{Ni}_{3} \mathrm{C}$ (reduction of $853.4 \mathrm{eV} \mathrm{Ni} 2 \mathrm{p}$ and vanishing $283.0 \mathrm{eV} \mathrm{C} \mathrm{1s}$ ) and suggests that this decomposition results in a mixture of metallic $\mathrm{Ni}$ (increasing $852.4 \mathrm{eV} \mathrm{Ni} 2 \mathrm{p}$ ) and $\mathrm{Ni}$ that still has a significant fraction of carbon interstitially dissolved $(\mathrm{Ni}(-\mathrm{C})$, nonvanishing intensity at $853.4 \mathrm{eV}$ in $\mathrm{Ni} 2 \mathrm{p}$ and $283.7 \mathrm{eV}$ in $\mathrm{C}$ $1 \mathrm{~s})$. Concomitantly, the disordered $\mathrm{sp}^{3}$-like carbon component (284.9 eV which was the predominant $\mathrm{C}$ 1s signal in the asloaded sample) reduces in relative intensity while the $\mathrm{sp}^{2}$ component $(284.4 \mathrm{eV})$ increases and becomes the new majority component. This is a first sign of graphitization. ${ }^{89}$ This XPS result at $300{ }^{\circ} \mathrm{C}$ implies a lower onset temperature of graphitization compared to the Raman data in Figure 4 above. XPS is however more sensitive to changes in local bonding environments (e.g., small disconnected regions transitioning from disordered carbon to $\mathrm{sp}^{2}$ ) while being less sensitive to the spatial extents of this bonding. In contrast, Raman spectroscopy is more suitable for probing the contiguous nature, i.e. crystallite size, of the bonded carbon. ${ }^{96}$ Therefore, the combination of in situ XPS and in situ Raman spectroscopy indicates that at $300{ }^{\circ} \mathrm{C}$ a transition of disordered carbon to $\mathrm{sp}^{2}$ bonding starts, but that the spatial extents of the formed $\mathrm{sp}^{2}$ regions remain very small.

Upon further increasing the annealing temperature to $550{ }^{\circ} \mathrm{C}$ and then $700{ }^{\circ} \mathrm{C}$, a further reduction of the disordered carbon component and increase of the $\mathrm{sp}^{2}$ component in the $\mathrm{C} 1 \mathrm{~s}$ is consistent with the emergence and growth of the $2 \mathrm{D}$ Raman peak and the corresponding decrease in $I(D) / I(G)$ ratio (Figure 4d). This shows that in this higher annealing temperature region $\left(550{ }^{\circ} \mathrm{C}\right.$ and above) spatially extended $\mathrm{sp}^{2}$-bonded graphitic regions are isothermally formed. (Further note that from 300 to $550{ }^{\circ} \mathrm{C}$ the $285.5 \mathrm{eV}$ component also disappears, which is indicative of the removal of adventitious carbon contamination. A minor residual $\mathrm{Ni}$ oxide component at $854.4 \mathrm{eV}$ remains throughout the experiment.) In contrast to the clear signs of graphitization observed in the $\mathrm{C} 1 \mathrm{~s}$, the $\mathrm{Ni} 2 \mathrm{p}$ fingerprint does not show significant further evolution with increasing temperatures from 300 to $700{ }^{\circ} \mathrm{C}$, implying that the chemical state of the mixture of metallic $\mathrm{Ni}$ and a $\mathrm{Ni}(-\mathrm{C})$ solid solution on the sample (sub)surface remains largely unchanged for annealing temperatures greater than $300{ }^{\circ} \mathrm{C}$.

Upon natural cooling in the vacuum neither the $\mathrm{C} 1 \mathrm{~s}$ nor the $\mathrm{Ni} 2 \mathrm{p}$ fingerprint changes significantly. In particular, the intensity of the $\mathrm{C} 1 \mathrm{~s}$ peak immediately after cooling is not higher than the $\mathrm{C} 1 \mathrm{~s}$ intensity at $700{ }^{\circ} \mathrm{C}$ immediately before cooling. This indicates that no significant amount of carbon precipitation to the sample surface has occurred upon natural cooling. This lack of additional carbon signal in the XPS data implies that the small increases in $I(G)$ and $I(D) / I(G)$ ratio seen in the in situ Raman data upon cooling (Figure 4c,d) do not relate to significant global precipitation of graphitic material to the sample surface. Instead, given the surface sensitivity of XPS compared to the more bulk-sensitive Raman spectrosco$\mathrm{py}^{20}$ it is suggested that upon natural cooling a small amount of deleterious carbon precipitates from the oversaturated $\mathrm{Ni}(-\mathrm{C})$ particles but remains localized at the direct $\mathrm{Ni}(-\mathrm{C}) /$ carbon matrix interface while the surface of the nanocomposite films is not strongly modified by carbon precipitation upon cooling. The conclusion that the amount of carbon precipitation is small is also corroborated by the preservation of the comparatively high $\mathrm{Ni}(-\mathrm{C})$ signal in the cooled films $(853.4 \mathrm{eV} \mathrm{Ni} 2 \mathrm{p} / 283.7$ 
eV C 1s) which implies that after natural cooling a significant amount of carbon is still interstitially dissolved in the $\mathrm{Ni}(-\mathrm{C})$ crystallites. This is also in good agreement with the comparably high carbon content of $0.19 \pm 0.07$ atom \% in the $\mathrm{Ni}$ after natural cooling, as estimated from the in situ XRD data above.

\section{DISCUSSION}

Evolution of Nickel (Carbide)/Carbon Nanocomposites. Based on our experimental results we now present a coherent model of thermally induced effects on metastable $\mathrm{Ni}$ carbide/a-C nanocomposites and contextualize the findings with respect to prior literature. See Figure 6 for a schematic illustration of the salient stages of this model.

Our as-deposited films show a structure of columnar metastable $\mathrm{Ni}_{3} \mathrm{C}$ crystals embedded in an a-C matrix. This morphology and its metastable nature are related to an interplay of repeated nucleation events and the dominance of surface diffusion effects during the nonequilibrium sputter deposition at room temperature, where bulk diffusion is considered to be negligible during film deposition. ${ }^{22,31,97}$ During the postdeposition heating studied here, the metastable system moves toward thermal equilibrium at elevated temperatures which enables several reaction pathways to become activated, including bulk-diffusion related mechanisms.

First, the as-deposited metastable $\mathrm{Ni}_{3} \mathrm{C}$ nanocrystallites in the a-C matrix isothermally decompose with a reaction onset temperature of $\sim 300{ }^{\circ} \mathrm{C}$, whereby metallic fcc $\mathrm{Ni}$ with interstitially dissolved carbon $(\mathrm{Ni}(-\mathrm{C}))$ is formed. At $300{ }^{\circ} \mathrm{C}$ the $\mathrm{Ni}(-\mathrm{C})$ is however oversaturated with carbon as the initial carbon content of $\mathrm{Ni}_{3} \mathrm{C}$ is 25 atom \% while fcc $\mathrm{Ni}$ at $300{ }^{\circ} \mathrm{C}$ has a maximum carbon solubility of $\sim 0.01$ atom \%. ${ }^{32,80}$ Thus, concurrent to the $\mathrm{Ni}_{3} \mathrm{C}$ to fcc $\mathrm{Ni}(-\mathrm{C})$ transformation, carbon is partially expelled by diffusion from the $\mathrm{Ni}(-\mathrm{C})$ particles due to the strong carbon oversaturation. At a low temperature of 300 ${ }^{\circ} \mathrm{C}$, we find that the expelled carbon cannot, however, rearrange into graphitic domains over the time scales considered but instead adds to the already present amorphous carbon matrix. This is consistent with recent ex situ work on decomposition and carbon shell formation for isolated, pure $\mathrm{Ni}_{3} \mathrm{C}$ nanocrystals. ${ }^{35,65,98}$ Thus, the overall isothermal $\mathrm{Ni}_{3} \mathrm{C}$ decomposition at $300{ }^{\circ} \mathrm{C}$ may be described by the two concurrent processes of a solid state phase transition coupled with a partial phase separation:

$$
\begin{aligned}
& \mathrm{Ni}_{3} \mathrm{C} \stackrel{300^{\circ} \mathrm{C}}{\longrightarrow} \mathrm{fcc} \mathrm{Ni}\left(-\mathrm{C}_{x+y}\right) \\
& \text { fcc Ni(- } \left.\mathrm{C}_{x+y}\right) \stackrel{300^{\circ} \mathrm{C}}{\longrightarrow} \mathrm{fcc} \mathrm{Ni}\left(-\mathrm{C}_{x}\right)+y \mathrm{a}-\mathrm{C}
\end{aligned}
$$

where $\mathrm{Ni}(-\mathrm{C})$ symbolizes a solid solution of carbon in fcc $\mathrm{Ni}$. The expelled $y$ a-C adds to the already initially present a-C matrix. Exact values for $x$ and $y$ remain unknown.

Concomitant grain growth of the Ni-based filler crystallites is observed to be very limited at $300{ }^{\circ} \mathrm{C}$ at the time scales considered. Therefore, annealing at $300{ }^{\circ} \mathrm{C}$ leaves the overall morphology of the nanocomposite thin films largely unchanged while only changing the crystallographic phase of the filler material. This shows that phase transformations and film morphology modifications can be decoupled in metastable nanocomposite films, which is highly desirable from a manufacturing perspective: For instance, our findings suggest that magnetic properties of the nanocomposites could be controlled without modification of the nanocomposite morphology since fcc $\mathrm{Ni}$ is ferromagnetic or superparamagnetic depending on particle size while $\mathrm{Ni}_{3} \mathrm{C}$ is in principle nonferromagnetic. ${ }^{12,21,99}$

Comparing to the wider literature, our observed decomposition of the a-C embedded $\mathrm{Ni}_{3} \mathrm{C}$ nanocrystallites at $300{ }^{\circ} \mathrm{C}$ on a tens of minutes time scale is faster than previously reported hour-long conversion processes at $\sim 300{ }^{\circ} \mathrm{C}$ for pure $\mathrm{Ni}_{3} \mathrm{C}$ crystallites. ${ }^{65,100,101}$ It is also lower in temperature compared to other reports which observed $>400{ }^{\circ} \mathrm{C}$ decomposition temperatures for pure isolated $\mathrm{Ni}_{3} \mathrm{C}$ crystals. $^{35,102}$ This may be related to a lower degree of order in our sputter-deposited $\mathrm{Ni}_{3} \mathrm{C}$ crystals, ${ }^{103}$ in particular in terms of the degree of order in the carbon sublattice within the hcp $\mathrm{Ni}$ parent phase. Thus, the state of the as-deposited Ni carbide used here may also be described as the recently suggested $\mathrm{Ni}$ carbide form hcp $\mathrm{NiC}_{y}$, which is comprised of a hcp $\mathrm{Ni}$ sublattice and a somewhat disordered interstitial carbon sublattice. $^{24}$ (See also the Supporting Information for a comment on $\mathrm{Ni}_{3} \mathrm{C}$ assignment/definition used here. ${ }^{24,64-66}$ ) We note that this could be a generic feature of similarly sputterdeposited nickel carbide/a-C nanocomposites, where commonly nickel carbide decomposition temperatures of around $300-400{ }^{\circ} \mathrm{C}$ are reported. ${ }^{6,12,13,28}$ The observed time dependence of isothermal decomposition at $300{ }^{\circ} \mathrm{C}$ for our films (inset in Figure $3 \mathrm{~b}$ ) can be fitted with the semiempirical JohnsonMehl-Avrami-Kolmogorov (JMAK) equation, ${ }^{104}$ wherefrom we estimate a maximum reaction rate ${ }^{105}$ of $r_{\max }=1 / t_{0.5} \sim$ $0.12 \% / \mathrm{s}$ at $300{ }^{\circ} \mathrm{C}$ and an Avrami exponent $n$ in the range $2.5-$ 4.1. The physical meaning of Avrami exponents for systems with complex concurrent reactions as in our system, where a solid state transition $\left(\mathrm{Ni}_{3} \mathrm{C} \rightarrow \mathrm{fcc} \mathrm{Ni}\left(-\mathrm{C}_{x+y}\right)\right)$ is coupled with a phase separation $\left(\mathrm{fcc} \mathrm{Ni}\left(-\mathrm{C}_{x+y}\right) \rightarrow \mathrm{fcc} \mathrm{Ni}\left(-\mathrm{C}_{x}\right)+y \mathrm{a}-\mathrm{C}\right)$ ), remains however under debate and Avrami coefficients alone are therefore normally not sufficient to robustly determine microscopic nucleation and growth mechanics. ${ }^{104}$

While annealing at $300{ }^{\circ} \mathrm{C}$ is sufficient to transform the initially present $\mathrm{Ni}_{3} \mathrm{C}$ nanocrystallites into fcc $\mathrm{Ni}(-\mathrm{C})$, only when the temperature is further increased (stepwise up to 800 ${ }^{\circ} \mathrm{C}$ ) do two further major processes become thermally activated: (1) a-C graphitization and (2) $\mathrm{Ni}$ grain growth and phase separation.

In the first process the a-C in the matrix (including the expelled carbon from the $\mathrm{Ni}_{3} \mathrm{C}$ decomposition) starts to graphitize into extended $\mathrm{sp}^{2}$-bonded regions ("nanocrystalline graphite”). Since direct, noncatalyzed a-C $\rightarrow$ graphitic carbon reactions are known to be negligible in the considered temperature region of $300-800{ }^{\circ} \mathrm{C},{ }^{31}$ the observed isothermal graphitization during heating from 400 to $700{ }^{\circ} \mathrm{C}$ suggests catalytic involvement of the $\mathrm{Ni}(-\mathrm{C})$ filler particles. As carbon solubility in fcc $\mathrm{Ni}$ increases with temperature, ${ }^{32}$ the observed graphitization is indicative of a dynamic Ni-bulk-mediated process in which carbon species from the a-C surroundings are taken up into the $\mathrm{Ni}(-\mathrm{C})$ particles upon increasing annealing temperature and subsequently nucleate as graphitic carbon while segregating from the $\mathrm{Ni}(-\mathrm{C})$ at temperature. ${ }^{70,106}$ Our in situ Raman data (Figure 4b) confirms that this Ni-catalyzed graphitization of the a-C matrix occurs upon heating and isothermal annealing. The reaction may be symbolized by

$$
\text { a-C } \stackrel{\mathrm{Ni}(-\mathrm{C}), 400-800^{\circ} \mathrm{C}}{\longrightarrow} \text { graphitic carbon }
$$

This resembles metal-induced-crystallization (MIC) phenomena in diverse materials systems such as metalcarbon, ${ }^{73,107}$ metal-Si, ${ }^{108}$ and metal-Ge. ${ }^{109}$ It is also 
reminiscent of carbon nanotube and graphene growth from gaseous $^{88,110,111}$ and solid state carbon ${ }^{72-74}$ sources, where also Ni-bulk- or Ni-subsurface-mediated graphitization has been suggested as a major mechanism. ${ }^{7,88,110,111}$ A significant difference from other MIC systems, however, is that in the present $\mathrm{Ni}-$ carbon nanocomposites the Ni-based crystallites are highly saturated with carbon at all stages of processing (including the as-deposited metastable $\mathrm{Ni}_{3} \mathrm{C}$ state) and MIC can quickly proceed when thermally activated without the requirement of further carbon take-up, while in other MIC systems typically major constituent dissolution has to precede the stages of supersaturation and crystallization onset.

Upon further increasing the annealing temperature in the range $400-800{ }^{\circ} \mathrm{C}$, the resulting $\mathrm{sp}^{2}$-bonded graphitic regions increase in crystallite size forming nanocrystalline graphite with grain sizes of $\sim 60 \mathrm{~nm}$. In contrast, in prior literature $\mathrm{Ni}$ has been shown to catalyze a-C to form high quality graphitic layers with micrometer lateral extents ${ }^{72}$ and has even been demonstrated to produce high-quality monolayer graphene during heating at $\sim 600{ }^{\circ} \mathrm{C}$ when carbon feeding is kinetically controlled to suitably low levels. ${ }^{74}$ To explain the comparably poor crystallite size of the graphitic material formed in our films, the kinetic aspects of the nanocomposite system evolution have to be considered: In the nanocomposite films examined here the overall carbon content is $\sim 70$ atom $\%$, which is significantly above the maximum carbon solubility in $\mathrm{Ni}$ at all stages of processing up to $800{ }^{\circ} \mathrm{C}$ (maximum carbon solubility in $\mathrm{Ni}$ at $800{ }^{\circ} \mathrm{C}$ is $\sim 0.5$ atom $\left.\%^{32,80}\right)$. Therefore, the $\mathrm{Ni}$ crystallites in our experiments are at all stages strongly overfed with carbon both from the already interstitially dissolved carbon and from the surrounding carbon matrix. The correspondingly high carbon arrival rates to the catalytically active $\mathrm{Ni}(-\mathrm{C})$ in turn impede formation of large area graphitic domains, as the graphite nucleation rates are too high and the resulting time scales are insufficient to heal out defects. Instead the high carbon content of the $\mathrm{Ni}(-\mathrm{C})$ particles throughout processing results in the observed nanocrystalline graphite formation in the carbon matrix. This situation is analogous to catalyst poisoning or coking mechanisms in classical heterogeneous catalysis. ${ }^{12}$ We emphasize that this highly bulk supersaturated nature at all processing stages and the intrinsically high carbon arrival rates from the surroundings are hallmark features of the thermal evolution mechanism in such metal/carbon nanocomposites, which clearly separates this class of materials from other metal-carbon systems where carbon influx to the interface can be controlled at lower rates, such as in balanced heterogeneous catalysis reactions ${ }^{112,113}$ or graphene ${ }^{35-42}$ and $\mathrm{CNT}^{45-59}$ growth from Ni catalysts.

The second process concurrent to a-C graphitization is grain growth in the $\mathrm{Ni}(-\mathrm{C})$ crystallites, which upon higher annealing temperatures destroys the fine nanometer-scale columnar grain structure of the nanocomposite films. Connected with the $\mathrm{Ni}$ (C) grain growth, the $\mathrm{Ni}(-\mathrm{C})$ particles and nanocrystalline graphite regions phase separate into a coarse film morphology for annealing up to $800{ }^{\circ} \mathrm{C}$. This is consistent with previous studies of such nanocomposite systems. ${ }^{6,31}$ It is interesting to note that compared to the ex situ studied $\mathrm{Co}-\mathrm{C}$ and $\mathrm{Cu}-\mathrm{C}$ systems in ref 31 , where upon phase separation the metal layer formed on top of the carbon layer, we find in our experiments the formation of a nanocrystalline graphite layer roughly on top of a Ni layer (Figure 1a). As suggested above, Ni-bulk-mediated diffusion effects are highly important for higher temperature annealing in our nanocomposites. In fact, we suggest that carbon diffusion through the bulk of the $\mathrm{Ni}(-\mathrm{C})$ particles links the above-described graphitization mechanism with the $\mathrm{Ni}$ grain growth and $\mathrm{Ni}-$ carbon phase separation. The main reason for this link is the comparably negligible self-diffusivity of carbon in amorphous carbon ${ }^{31}$ which results in the $\mathrm{Ni}$ particles being the primary pathway for any possible carbon rearrangement. Throughout this carbon rearrangement process the Ni particles, however, do not remain statically embedded in the mobile, graphitizing carbon matrix but instead undergo grain growth and become mobile themselves. Previous TEM studies of $\mathrm{Ni}$ nanocrystals on a-C films also support a strong link between increasing Ni crystal mobility/reshaping and a-C graphitization. ${ }^{69,70}$ Thus, we identify dynamic uptake and loss of carbon from/into the carbon matrix as a major governing factor for $\mathrm{Ni}(-\mathrm{C})$ particle evolution, where again the very high carbon content at all stages of processing is a distinctive feature of metal-carbon nanocomposite thin film systems such as ours.

Upon natural cooling the film morphologies are largely preserved, even when cooling from high temperature. Despite a significant decrease in thermodynamically predicted carbon solubility $\left(0.5\right.$ atom $\%$ at $800{ }^{\circ} \mathrm{C}$ to $<0.01$ atom $\%$ at room temperature $\left.\mathrm{r}^{32,80}\right)$ in the $\mathrm{Ni}(-\mathrm{C})$ particles upon cooling, we find from in situ XPS and XRD only limited signs of actual carbon precipitation upon cooling and instead find that still significant amounts of carbon remain dissolved interstitially in the $\mathrm{Ni}$ crystallites even after cooling. The estimated carbon content from in situ XRD after cooling from $800{ }^{\circ} \mathrm{C}$ to room temperature was $0.19 \pm 0.07$ atom $\%$ in the $\mathrm{Ni}$, which would correspond to the expected equilibrium carbon content in $\mathrm{Ni}$ for temperatures between 580 and $690{ }^{\circ} \mathrm{C} .{ }^{80}$ The process upon cooling may thus be described as

$$
\mathrm{fcc} \mathrm{Ni}\left(-\mathrm{C}_{a+b}\right) \stackrel{\text { cool }}{\longrightarrow} \mathrm{fcc} \mathrm{Ni}\left(-\mathrm{C}_{a}\right)+b \mathrm{a}-\mathrm{C} \quad \text { with } a \gg b
$$

We suggest that two factors hinder extensive carbon precipitation out of the $\mathrm{Ni}$ at natural cooling rates in our experiments: First, the concentration-gradient-driven diffusion of carbon out of the $\mathrm{Ni}(-\mathrm{C})$ is small since outward carbon diffusion is directed toward the interface to a fully carbon saturated matrix (nanocrystalline graphite in matrix). This is a generic feature of two-phase nanocomposite thin films which show small but finite miscibility. Second, the diffusivity of carbon in $\mathrm{Ni}(-\mathrm{C})$ is comparatively slow in transporting significant carbon out of the $\mathrm{Ni}(-\mathrm{C})$ toward the $\mathrm{Ni}(-\mathrm{C})$ / nanocrystalline graphite interface for the cooling rates used here. ${ }^{110,114}$ Upon reaching this interface, then the almost negligible self-diffusivity of carbon in a-C or graphite ${ }^{31}$ hinders onward carbon transport, thus locking precipitated carbon at the $\mathrm{Ni}(-\mathrm{C})$ interface. Combined, these factors prohibit significant carbon precipitation from the $\mathrm{Ni}$ crystallites to the sample surface upon natural cooling, and thus allow nanocomposite structure engineering predominantly based on the selection of the heating rate and treatment temperature instead of technically more demanding cooling rate selection via, e.g., controlled quenching.

Overall, the structural and morphological nanocomposite evolution during annealing that is observed in situ here is consistent with recent ex situ work on $\mathrm{Ni}$ (carbide)/a-C films ${ }^{28}$ and on Co (carbide)/a-C nanocomposites, ${ }^{31}$ where similarly low temperature carbide disintegration and higher temperature graphitization and phase separation were inferred from ex situ measurements. This emphasizes the generic nature of our in situ findings. While the films studied here were deposited at 
nonequilibrium conditions at room temperature, we note that the here observed mechanisms are also relevant for nanocomposite sputter deposition at elevated temperatures (i.e., with intentional substrate heating), where nonequilibrium effects $^{22,31,97}$ from the deposition process and thermally induced processes are active in parallel. This conclusion is consistent with the previously reported properties of $\mathrm{Ni}-$ carbon nanocomposites that were sputter deposited at increasingly elevated deposition temperatures. ${ }^{14,15,17-21,26}$

$\mathrm{Ni}_{3} \mathrm{C}$ as a Possible Graphene/CNT Growth Catalyst. Beyond its application as a functional coating, metastable $\mathrm{Ni}_{3} \mathrm{C}$ has also been recently discussed as an intermediate catalyst phase in graphene ${ }^{35-44}$ synthesis via CVD and solid-state growth as well as in CNT CVD. ${ }^{45-60}$ To date, there is however a lack of in situ studies with $\mathrm{Ni}_{3} \mathrm{C}$ to directly elucidate the metastable carbide's role in graphene and CNT growth. Therefore, our findings here may also serve as a first approximate model system analogue for graphene and CNT growth from $\mathrm{Ni}_{3} \mathrm{C}$ catalysts.

Typical temperatures for CVD and solid state growth of graphene and CNTs range from 450 to $1000{ }^{\circ} \mathrm{C}$. Thus, the fast decomposition of $\mathrm{Ni}_{3} \mathrm{C}$ observed here at temperatures as low as $300{ }^{\circ} \mathrm{C}$ suggests that it is unlikely that a crystalline bulk $\mathrm{Ni}_{3} \mathrm{C}$ carbide is involved in Ni-catalyzed graphitic nanostructure growth under typical graphene and CNT growth conditions, especially for typical growth temperatures above $300{ }^{\circ} \mathrm{C}$ and common holding/growth times in the range of minutes. Our in situ observations thereby experimentally reaffirm recent theoretical work that similarly suggests that crystalline bulk $\mathrm{Ni}_{3} \mathrm{C}$ is unlikely to directly partake in graphene formation because, as here, crystalline $\mathrm{Ni}_{3} \mathrm{C}$ was found to decompose already prior to extended growth of graphitic material. ${ }^{39}$ In turn, our results suggest that, in the higher temperature range typically used $\left(>300^{\circ} \mathrm{C}\right)$, it is not bulk $\mathrm{Ni}_{3} \mathrm{C}$ but rather $\mathrm{Ni}_{3} \mathrm{C}$ 's decomposition product, a solid solution of carbon in fcc Ni $(\mathrm{Ni}(-\mathrm{C}))$, which is the active graphene and CNT growth catalyst phase. This is in excellent agreement with previous in situ studies on $\mathrm{CVD}^{88,110,115}$ and solid state growth ${ }^{74}$ of graphene from $\mathrm{Ni}$ catalysts that have excluded the formation of a structural $\mathrm{Ni}_{3} \mathrm{C}$ bulk carbide during graphene formation (while a monolayer thin $\mathrm{Ni}_{2} \mathrm{C}$ carbide surface reconstruction can partake under certain low temperature graphene growth conditions $^{91}$ ). Our observations here now suggest that, even when crystalline bulk $\mathrm{Ni}_{3} \mathrm{C}$ is the starting catalyst material in graphene or CNT growth, the facile thermal decomposition of bulk $\mathrm{Ni}_{3} \mathrm{C}$ toward $\mathrm{Ni}(-\mathrm{C})$ precedes the graphitization of carbon, thus resulting in $\mathrm{Ni}(-\mathrm{C})$ being the actual active catalyst bulk phase of graphene and CNT growth under typical conditions. Exceptions may include growth conditions with exceptionally high heating rates ${ }^{37,41}$ or nonequilibrium conditions where, e.g., Ni precursors are continuously fed during the graphitic material growth. ${ }^{59}$ This is in contrast to catalysts which are comparably stronger carbide formers (such as $\mathrm{Fe}$ ) where thermodynamically stable carbide bulk phases can readily partake in carbon nanostructure growth. ${ }^{76,78}$

\section{CONCLUSIONS}

In summary, we employed complementary in situ characterization to identify key factors governing thermally induced phase transitions in metastable $\mathrm{Ni}_{3} \mathrm{C} / \mathrm{a}-\mathrm{C}$ nanocomposites. At low temperature $\left(300{ }^{\circ} \mathrm{C}\right)$ isothermal decomposition of the $\mathrm{Ni}_{3} \mathrm{C}$ filler phase into fcc $\mathrm{Ni}(-\mathrm{C})$ and a-C occurs, where the released carbon further adds to the carbon matrix. The finely nanoscaled morphology of the composites remains however preserved at the low annealing temperature. In contrast, isothermal Ni-catalyzed graphitization of the amorphous carbon matrix and a linked bulk-diffusion-mediated phase separation into coarse $\mathrm{Ni}$ and nanocrystalline graphite grains sets in only at higher temperatures $\left(400-800{ }^{\circ} \mathrm{C}\right)$. This shows that filler phase transformations and nanocomposite morphology modifications can be decoupled upon thermal postdeposition processing which is technologically advantageous. Precipitation of additional carbon from the $\mathrm{Ni}$ upon cooling was found to be minor for natural cooling rates. Our findings suggest that the high carbon content of the Ni filler crystallites at all stages of processing is the key property of such metal (carbide)/carbon nanocomposites that determines their thermal evolution. In the wider context of the recently much debated role of $\mathrm{Ni}_{3} \mathrm{C}$ as a graphene and CNT growth catalyst, the low stability of $\mathrm{Ni}_{3} \mathrm{C}$ directly observed here suggests that it is not bulk $\mathrm{Ni}_{3} \mathrm{C}$ but fcc $\mathrm{Ni}(-\mathrm{C})$ that is the active bulk catalyst phase under typical graphene/CNT growth conditions.

\section{ASSOCIATED CONTENT}

\section{Supporting Information}

The Supporting Information is available free of charge on the ACS Publications website at DOI: 10.1021/acs.jpcc.6b01555.

Detailed experimental methods description; comments on estimation of temperatures and $\mathrm{Ni}_{3} \mathrm{C}$ phase definition/assignment; table of XPS BE assignments (PDF)

\section{AUTHOR INFORMATION}

\section{Corresponding Author}

*E-mail: bernhard.bayer@univie.ac.at. Tel.: +43-1-4277-72870. Notes

The authors declare no competing financial interest.

\section{ACKNOWLEDGMENTS}

B.C.B. acknowledges funding from the European Union's Horizon 2020 research and innovation program under the Marie Skłodowska-Curie Grant Agreement No. 6562142DInterFOX. J.C.M. acknowledges support from the Austrian Science Fund (FWF): P25721-N20. We also acknowledge support from the Austrian Research Promotion Agency (FFG): 848152-GraphenMoFET. D.A.B. acknowledges funding from EPSRC. R.S.W. acknowledges a Research Fellowship from St. John's College, Cambridge, and a Marie Skłodowska-Curie Individual Fellowship (Global) under grant ARTIST (No. 656870) from the European Union's Horizon 2020 research and innovation program. P.R.K. acknowledges the Lindemann Trust fellowship. S.H. acknowledges funding from ERC grant InsituNANO (No. 279342). J.J.B. acknowledges financial support from EPSRC grants EP/G060649/1, EP/L027151/1 and EP/I012060/1, and ERC grant LINASS 320503. We acknowledge S. Newcomb, Glebe Scientific Ltd., Ireland, and M. Ward, LENNF/Leeds University, U.K., for contributing to the TEM measurements. We acknowledge the European Synchrotron Radiation Facility (ESRF) and the HelmholtzZentrum-Berlin Electron storage ring BESSY II for provision of synchrotron radiation facilities.

\section{REFERENCES}

(1) Ajayan, P. M.; Schadler, L. S.; Braun, P. V. Nanocomposite Science and Technology; John Wiley \& Sons: 2006. 
(2) Dimigen, H.; Hübsch, H.; Memming, R. Tribological and Electrical Properties of Metal-containing Hydrogenated Carbon Films. Appl. Phys. Lett. 1987, 50, 1056-1058.

(3) Kot, M.; Major, Ł.; Chronowska-Przywara, K.; Lackner, J.; Waldhauser, W.; Rakowski, W. The Advantages of Incorporating CrxC Nanograins into an aC: H Matrix in Tribological Coatings. Mater. Eng. 2014, 56, 981-989.

(4) Fonseca, F.; Ferlauto, A.; Alvarez, F.; Goya, G.; Jardim, R. Morphological and Magnetic Properties of Carbon-nickel Nanocomposite Thin Films. J. Appl. Phys. 2005, 97, 044313.

(5) Pisana, S.; Mosendz, O.; Parker, G.; Reiner, J.; Santos, T.; McCallum, A.; Richter, H.; Weller, D. Effects of Grain Microstructure on Magnetic Properties in FePtAg-C Media for Heat Assisted Magnetic Recording. J. Appl. Phys. 2013, 113, 043910.

(6) Koppert, R.; Uhlig, S.; Schmid-Engel, H.; Göttel, D.; Probst, A.C.; Schultes, G.; Werner, U. Structural and Physical Properties of Highly Piezoresistive Nickel Containing Hydrogenated Carbon Thin Films. Diamond Relat. Mater. 2012, 25, 50-58.

(7) Hong, Z.-C.; Shiue, S.-T. Effects of Annealing Temperature on Characteristics of Amorphous Nickel Carbon Thin Film Alloys Deposited on N-Type Silicon Substrates by Reactive Sputtering. Thin Solid Films 2016, DOI: 10.1016/j.tsf.2016.04.032.

(8) Haslam, G. E.; Chin, X.-Y.; Burstein, G. T. Passivity and Electrocatalysis of Nanostructured Nickel Encapsulated in Carbon. Phys. Chem. Chem. Phys. 2011, 13, 12968-12974.

(9) Ingham, B.; Gaston, N.; Fahy, K.; Chin, X. Y.; Dotzler, C. J.; Rees, E.; Haslam, G.; Barber, Z. H.; Burstein, G. T.; Ryan, M. P. Extended XRay Absorption Fine Structure and X-Ray Diffraction Examination of Sputtered Nickel Carbon Binary Thin Films for Fuel Cell Applications. J. Phys. Chem. C 2012, 116, 6159-6165.

(10) Bettini, L. G.; Divitini, G.; Ducati, C.; Milani, P.; Piseri, P. Nickel Nanoparticles Effect on the Electrochemical Energy Storage Properties of Carbon Nanocomposite Films. Nanotechnology 2014, 25, 435401.

(11) Jansson, U.; Lewin, E. Sputter Deposition of Transition-Metal Carbide films-A Critical Review from a Chemical Perspective. Thin Solid Films 2013, 536, 1-24.

(12) Mamezaki, O.; Adachi, H.; Tomita, S.; Fujii, M.; Hayashi, S. Thin Films of Carbon Nanocapsules and Onion-like Graphitic Particles Prepared by the Cosputtering Method. Jpn. J. Appl. Phys. 2000, 39, 6680 .

(13) Shi, J.; Hashiba, Y.; Nittono, O. Preparation and Characterization of Ni-C Composite Films. J. Mater. Sci. 2001, 36, 343-349.

(14) Kovács, G. J.; Sáfrán, G.; Geszti, O.; Ujvári, T.; Bertóti, I.; Radnóczi, G. Structure and Mechanical Properties of Carbon-nickel and $\mathrm{CNx}-$ nickel Nanocomposite Films. Surf. Coat. Technol. 2004, 180, 331-334.

(15) Sedláčková, K.; Lobotka, P.; Vávra, I.; Radnóczi, G. Structural, Electrical and Magnetic Properties of Carbon-nickel Composite Thin Films. Carbon 2005, 43, 2192-2198.

(16) Kukiełka, S.; Gulbiński, W.; Pauleau, Y.; Dub, S.; Grob, J. Composition, Mechanical Properties and Friction Behavior of Nickel/ hydrogenated Amorphous Carbon Composite Films. Surf. Coat. Technol. 2006, 200, 6258-6262.

(17) Sedláčková, K.; Czigany, Z.; Ujvari, T.; Bertoti, I.; Grasin, R.; Kovacs, G. J.; Radnoczi, G. The Effect of the Carbon Matrix on the Mechanical Properties of Nanocomposite Films Containing Nickel Nanoparticles. Nanotechnology 2007, 18, 445604.

(18) Kovács, G. J.; Veres, M.; Koós, M.; Radnóczi, G. Raman Spectroscopic Study of Magnetron Sputtered Carbon-nickel and Carbon Nitride-nickel Composite Films: The Effect of Nickel on the Atomic Structure of the C/CNx Matrix. Thin Solid Films 2008, 516, 7910-7915.

(19) Kovács, G. J.; Bertóti, I.; Radnóczi, G. X-Ray Photoelectron Spectroscopic Study of Magnetron Sputtered Carbon-nickel Composite Films. Thin Solid Films 2008, 516, 7942-7946.

(20) Abrasonis, G.; Krause, M.; Mücklich, A.; Sedlackova, K.; Radnóczi, G.; Kreissig, U.; Kolitsch, A.; Möller, W. Growth Regimes and Metal Enhanced 6-Fold Ring Clustering of Carbon in Carbonnickel Composite Thin Films. Carbon 2007, 45, 2995-3006.

(21) Abrasonis, G.; Scheinost, A. C.; Zhou, S.; Torres, R.; Gago, R.; Jiménez, I.; Kuepper, K.; Potzger, K.; Krause, M.; Kolitsch, A.; et al. XRay Spectroscopic and Magnetic Investigation of C:Ni Nanocomposite Films Grown by Ion Beam Cosputtering. J. Phys. Chem. C 2008, 112, 12628-12637.

(22) El Mel, A.; Bouts, N.; Grigore, E.; Gautron, E.; Granier, A.; Angleraud, B.; Tessier, P. Shape Control of Nickel Nanostructures Incorporated in Amorphous Carbon Films: From Globular Nanoparticles toward Aligned Nanowires. J. Appl. Phys. 2012, 111, 114309.

(23) Bosworth, D. A.; Stelmashenko, N. A.; Barber, Z. H. Structural Control of Carbon Nickel Nano-Composite Thin Films without Substrate Heating. Thin Solid Films 2013, 540, 10-16.

(24) Furlan, A.; Lu, J.; Hultman, L.; Jansson, U.; Magnuson, M. Crystallization Characteristics and Chemical Bonding Properties of Nickel Carbide Thin Film Nanocomposites. J. Phys.: Condens. Matter 2014, 26, 415501.

(25) Kelling, J.; Zahn, P.; Schuster, J.; Gemming, S. Elastic and Piezoresistive Properties of Nickel Carbides from First-Principles. 2016, arXiv:1604.00328 [cond-mat.mtrl-sci]. arXiv.org e-Print archive. https://arxiv.org/abs/1604.00328.

(26) Abrasonis, G.; Kovacs, G. J.; Ryves, L.; Krause, M.; Mücklich, A.; Munnik, F.; Oates, T.; Bilek, M.; Möller, W. Phase Separation in Carbon-Nickel Films during Hyperthermal Ion Deposition. J. Appl. Phys. 2009, 105, 083518.

(27) Abrasonis, G.; Kovács, G. J.; Tucker, M. D.; Heller, R.; Krause, M.; Guenette, M. C.; Munnik, F.; Lehmann, J.; Tadich, A.; Cowie, B. C. C.; et al. Sculpting Nanoscale Precipitation Patterns in Nanocomposite Thin Films via Hyperthermal Ion Deposition. Appl. Phys. Lett. 2010, 97, 163108.

(28) El Mel, A.; Gautron, E.; Angleraud, B.; Granier, A.; Tessier, P. Synthesis of Nickel-Filled Carbon Nanotubes at $350^{\circ}$ C. Carbon 2011, 49, 4595-4598.

(29) Krause, M.; Mücklich, A.; Oates, T. W.; Zschornak, M.; Wintz, S.; Endrino, J. L.; Baehtz, C.; Shalimov, A.; Gemming, S.; Abrasonis, G. Tilting of Carbon Encapsulated Metallic Nanocolumns in CarbonNickel Nanocomposite Films by Ion Beam Assisted Deposition. Appl. Phys. Lett. 2012, 101, 053112.

(30) Krause, M.; Buljan, M.; Mücklich, A.; Möller, W.; Fritzsche, M.; Facsko, S.; Heller, R.; Zschornak, M.; Wintz, S.; Endrino, J. L.; et al. Compositionally Modulated Ripples during Composite Film Growth: Three-Dimensional Pattern Formation at the Nanoscale. Phys. Rev. B: Condens. Matter Mater. Phys. 2014, 89, 085418.

(31) Berndt, M.; Abrasonis, G.; Kovács, G. J.; Krause, M.; Munnik, F.; Heller, R.; Kolitsch, A.; Möller, W. Bulk Diffusion Induced Structural Modifications of Carbon-Transition Metal Nanocomposite Films. J. Appl. Phys. 2011, 109, 063503.

(32) Singleton, M.; Nash, P. The C-Ni (Carbon-Nickel) System. Bull. Alloy Phase Diagrams 1989, 10, 121-126.

(33) Gibson, J. S.; Uddin, J.; Cundari, T. R.; Bodiford, N. K.; Wilson, A. K. First-Principle Study of Structure and Stability of Nickel Carbides. J. Phys.: Condens. Matter 2010, 22, 445503.

(34) Fang, C.; Sluiter, M.; Van Huis, M.; Zandbergen, H. Structural and Magnetic Properties of $\mathrm{NiC} \mathrm{X}$ and $\mathrm{NiN} \mathrm{X} \mathrm{(X=0} \mathrm{to} 13$ ) Solid Solutions from First-Principles Calculations. Phys. Rev. B: Condens. Matter Mater. Phys. 2012, 86, 134114

(35) Yoon, S.-M.; Choi, W. M.; Baik, H.; Shin, H.-J.; Song, I.; Kwon, M.-S.; Bae, J. J.; Kim, H.; Lee, Y. H.; Choi, J.-Y. Synthesis of Multilayer Graphene Balls by Carbon Segregation from Nickel Nanoparticles. ACS Nano 2012, 6, 6803-6811.

(36) Cao, Y.; Su, Q.; Che, R.; Du, G.; Xu, B. One-Step Chemical Vapor Synthesis of $\mathrm{Ni} /$ graphene Nanocomposites with Excellent Electromagnetic and Electrocatalytic Properties. Synth. Met. 2012, 162, 968-973.

(37) Xiong, W.; Zhou, Y. S.; Jiang, L. J.; Sarkar, A.; Mahjouri-Samani, M.; Xie, Z. Q.; Gao, Y.; Ianno, N. J.; Jiang, L.; Lu, Y. F. Single-Step Formation of Graphene on Dielectric Surfaces. Adv. Mater. 2013, 25, $630-634$. 
(38) Jiao, M.; Qian, H.; Page, A.; Li, K.; Wang, Y.; Wu, Z.; Irle, S.; Morokuma, K. Graphene Nucleation from Amorphous Nickel Carbides: $\mathrm{QM} / \mathrm{MD}$ Studies on the Role of Subsurface Carbon Density. J. Phys. Chem. C 2014, 118, 11078-11084.

(39) Jiao, M.; Li, K.; Guan, W.; Wang, Y.; Wu, Z.; Page, A.; Morokuma, K. Crystalline Ni3C as Both Carbon Source and Catalyst for Graphene Nucleation: A QM/MD Study. Sci. Rep. 2015, 5, 12091.

(40) Son, I. H.; Song, H. J.; Kwon, S.; Bachmatiuk, A.; Lee, S. J.; Benayad, A.; Park, J. H.; Choi, J.-Y.; Chang, H.; Rümmeli, M. H. CO2 Enhanced Chemical Vapor Deposition Growth of Few-Layer Graphene over NiO X. ACS Nano 2014, 8, 9224-9232.

(41) Xiong, W.; Zhou, Y. S.; Hou, W. J.; Guillemet, T.; Silvain, J. F.; Gao, Y.; Lahaye, M.; Lebraud, E.; Xu, S.; Wang, X. W.; et al. SolidState Graphene Formation via a Nickel Carbide Intermediate Phase. RSC Adv. 2015, 5, 99037-99043.

(42) Seah, C.-M.; Vigolo, B.; Chai, S.-P.; Ichikawa, S.; Gleize, J.; Le Normand, F.; Aweke, F.; Mohamed, A. R. Sequential Synthesis of Free-Standing High Quality Bilayer Graphene from Recycled Nickel Foil. Carbon 2016, 96, 268-275.

(43) Zhizhin, E.; Pudikov, D.; Rybkin, A.; Petukhov, A.; Zhukov, Y.; Shikin, A. Growth of Graphene Monolayer by "internal Solid-State Carbon Source": Electronic Structure, Morphology and Au Intercalation. Mater. Des. 2016, 104, 284-291.

(44) Chen, S.; Xiong, W.; Zhou, Y. S.; Lu, Y. F.; Zeng, X. C. An Ab Initio Study of the Nickel-Catalyzed Transformation of Amorphous Carbon into Graphene in Rapid Thermal Processing. Nanoscale 2016, 8, 9746-9755.

(45) Arie, T.; Nishijima, H.; Akita, S.; Nakayama, Y. CarbonNanotube Probe Equipped Magnetic Force Microscope. J. Vac. Sci. Technol., B: Microelectron. Process. Phenom. 2000, 18, 104-106.

(46) Ducati, C.; Alexandrou, I.; Chhowalla, M.; Robertson, J.; Amaratunga, G. The Role of the Catalytic Particle in the Growth of Carbon Nanotubes by Plasma Enhanced Chemical Vapor Deposition. J. Appl. Phys. 2004, 95, 6387-6391.

(47) Lin, M.; Ying Tan, J. P.; Boothroyd, C.; Loh, K. P.; Tok, E. S.; Foo, Y.-L. Direct Observation of Single-Walled Carbon Nanotube Growth at the Atomistic Scale. Nano Lett. 2006, 6, 449-452.

(48) Esconjauregui, S.; Whelan, C. M.; Maex, K. The Reasons Why Metals Catalyze the Nucleation and Growth of Carbon Nanotubes and Other Carbon Nanomorphologies. Carbon 2009, 47, 659-669.

(49) Rinaldi, A.; Abdullah, N.; Ali, M.; Furche, A.; Hamid, S. B. A.; Su, D. S.; Schlögl, R. Controlling the Yield and Structure of Carbon Nanofibers Grown on a Nickel/activated Carbon Catalyst. Carbon 2009, 47, 3023-3033.

(50) Sharma, R.; Chee, S.-W.; Herzing, A.; Miranda, R.; Rez, P. Evaluation of the Role of $\mathrm{Au}$ in Improving Catalytic Activity of $\mathrm{Ni}$ Nanoparticles for the Formation of One-Dimensional Carbon Nanostructures. Nano Lett. 2011, 11, 2464-2471.

(51) Pigos, E.; Penev, E. S.; Ribas, M. A.; Sharma, R.; Yakobson, B. I.; Harutyunyan, A. R. Carbon Nanotube Nucleation Driven by Catalyst Morphology Dynamics. ACS Nano 2011, 5, 10096-10101.

(52) Rinaldi, A.; Tessonnier, J.; Schuster, M. E.; Blume, R.; Girgsdies, F.; Zhang, Q.; Jacob, T.; Abd Hamid, S. B.; Su, D. S.; Schlögl, R. Dissolved Carbon Controls the Initial Stages of Nanocarbon Growth. Angew. Chem., Int. Ed. 2011, 50, 3313-3317.

(53) Panagiotopoulos, N. T.; Diamanti, E. K.; Koutsokeras, L. E.; Baikousi, M.; Kordatos, E.; Matikas, T. E.; Gournis, D.; Patsalas, P. Nanocomposite Catalysts Producing Durable, Super-Black Carbon Nanotube Systems: Applications in Solar Thermal Harvesting. ACS Nano 2012, 6, 10475-10485.

(54) Krause, M.; Haluška, M.; Abrasonis, G.; Gemming, S. SWCNT Growth from C: Ni Nanocomposites. Phys. Status Solidi B 2012, 249, 2357-2360.

(55) Mohammad, S. N. Unified Platform for the Chemical Reactivity and Catalytic Potential of Catalyst Nanoparticles of Even Very Diverse Structures and Characteristics for Nanotube (Including Carbon Nanotube) Syntheses. J. Mater. Chem. 2012, 22, 21560-21582.

(56) Achour, A.; El Mel, A.; Bouts, N.; Gautron, E.; Grigore, E.; Angleraud, B.; Le Brizoual, L.; Tessier, P.; Djouadi, M. Carbon
Nanotube Growth at $420^{\circ} \mathrm{C}$ Using Nickel/carbon Composite Thin Films as Catalyst Supports. Diamond Relat. Mater. 2013, 34, 76-83.

(57) Yu, B.; Wang, S.; Zhang, Q.; He, Y.; Huang, H.; Zou, J. Ni3CAssisted Growth of Carbon Nanofibres $300^{\circ} \mathrm{C}$ by Thermal CVD. Nanotechnology 2014, 25, 325602.

(58) Gómez-Gualdrón, D. A.; Beetge, J. M.; Balbuena, P. B. Characterization of Metal Nanocatalyst State and Morphology during Simulated Single-Walled Carbon Nanotube Growth. J. Phys. Chem. C 2013, 117, 12061-12070.

(59) Yu, B.; Zhang, Q.; Hou, L.; Wang, S.; Song, M.; He, Y.; Huang, H.; Zou, J. Temperature-Dependent Chemical State of the Nickel Catalyst for the Growth of Carbon Nanofibers. Carbon 2016, 96, 904910.

(60) Melkhanova, S.; Haluska, M.; Hübner, R.; Kunze, T.; Keller, A.; Abrasonis, G.; Gemming, S.; Krause, M. Carbon: Nickel Nanocomposite Templates-predefined Stable Catalysts for DiameterControlled Growth of Single-Walled Carbon Nanotubes. Nanoscale 2016, 8, 14888-14897.

(61) Bayer, B. C.; Sanjabi, S.; Baehtz, C.; Wirth, C. T.; Esconjauregui, S.; Weatherup, R. S.; Barber, Z. H.; Hofmann, S.; Robertson, J. Carbon Nanotube Forest Growth on NiTi Shape Memory Alloy Thin Films for Thermal Actuation. Thin Solid Films 2011, 519, 6126-6129.

(62) Bayer, B. C.; Khan, A. F.; Mehmood, M.; Barber, Z. H. Effect of Substrate on Processing of Multi-Gun Sputter Deposited, nearStoichiometric Ni2MnGa Thin Films. Thin Solid Films 2010, 518, 2659-2664.

(63) Gammer, C.; Mangler, C.; Rentenberger, C.; Karnthaler, H. Quantitative Local Profile Analysis of Nanomaterials by Electron Diffraction. Scr. Mater. 2010, 63, 312-315.

(64) Schaefer, Z. L.; Weeber, K. M.; Misra, R.; Schiffer, P.; Schaak, R. E. Bridging Hcp-Ni and Ni3C via a Ni3C1-X Solid Solution: Tunable Composition and Magnetism in Colloidal Nickel Carbide Nanoparticles. Chem. Mater. 2011, 23, 2475-2480.

(65) Chiang, R.-T.; Chiang, R.-K.; Shieu, F.-S. Emergence of Interstitial-Atom-Free HCP Nickel Phase during the Thermal Decomposition of Ni 3 C Nanoparticles. RSC Adv. 2014, 4, 1948819494.

(66) Uhlig, S.; Struis, R.; Schmid-Engel, H.; Bock, J.; Probst, A.-C.; Freitag-Weber, O.; Zizak, I.; Chernikov, R.; Schultes, G. Piezoresistive $\mathrm{Ni}$ aC: $\mathrm{H}$ Thin Films Containing Hcp-Ni or Ni $3 \mathrm{C}$ Investigated by XRD, EXAFS, and Wavelet Analysis. Diamond Relat. Mater. 2013, 34, $25-35$.

(67) Ferrari, A. C. Raman Spectroscopy of Graphene and Graphite: Disorder, Electron-phonon Coupling, Doping and Nonadiabatic Effects. Solid State Commun. 2007, 143, 47-57.

(68) Kidambi, P. R.; Bayer, B. C.; Weatherup, R. S.; Ochs, R.; Ducati, C.; Szabó, D. V.; Hofmann, S. Hafnia Nanoparticles-a Model System for Graphene Growth on a Dielectric. Phys. Status Solidi RRL 2011, 5, 341-343.

(69) Anton, R. On the Reaction Kinetics of Ni with Amorphous Carbon. Carbon 2008, 46, 656-662.

(70) Lamber, R; Jaeger, N.; Schulz-Ekloff, G. Electron Microscopy Study of the Interaction of $\mathrm{Ni}, \mathrm{Pd}$ and $\mathrm{Pt}$ with Carbon: I. Nickel Catalyzed Graphitization of Amorphous Carbon. Surf. Sci. 1988, 197, 402-414.

(71) Derbyshire, F.; Presland, A.; Trimm, D. Graphite Formation by the Dissolution-precipitation of Carbon in Cobalt, Nickel and Iron. Carbon 1975, 13, 111-113.

(72) Zheng, M.; Takei, K.; Hsia, B.; Fang, H.; Zhang, X.; Ferralis, N.; Ko, H.; Chueh, Y.-L.; Zhang, Y.; Maboudian, R.; et al. Metal-Catalyzed Crystallization of Amorphous Carbon to Graphene. Appl. Phys. Lett. 2010, 96, 063110.

(73) Saenger, K.; Tsang, J.; Bol, A.; Chu, J.; Grill, A.; Lavoie, C. In Situ X-Ray Diffraction Study of Graphitic Carbon Formed during Heating and Cooling of Amorphous-C/Ni Bilayers. Appl. Phys. Lett. 2010, 96, 153105 .

(74) Weatherup, R. S.; Baehtz, C.; Dlubak, B.; Bayer, B. C.; Kidambi, P. R.; Blume, R.; Schloegl, R.; Hofmann, S. Introducing Carbon 
Diffusion Barriers for Uniform, High-Quality Graphene Growth from Solid Sources. Nano Lett. 2013, 13, 4624-4631.

(75) Wenisch, R.; Hübner, R.; Munnik, F.; Melkhanova, S.; Gemming, S.; Abrasonis, G.; Krause, M. Nickel-Enhanced Graphitic Ordering of Carbon Ad-Atoms during Physical Vapor Deposition. Carbon 2016, 100, 656-663.

(76) Wirth, C. T.; Bayer, B. C.; Gamalski, A. D.; Esconjauregui, S.; Weatherup, R. S.; Ducati, C.; Baehtz, C.; Robertson, J.; Hofmann, S. The Phase of Iron Catalyst Nanoparticles during Carbon Nanotube Growth. Chem. Mater. 2012, 24, 4633-4640.

(77) Kidambi, P. R.; Blume, R.; Kling, J.; Wagner, J. B.; Baehtz, C.; Weatherup, R. S.; Schlögl, R.; Bayer, B. C.; Hofmann, S. In Situ Observations during Chemical Vapor Deposition of Hexagonal Boron Nitride on Polycrystalline Copper. Chem. Mater. 2014, 26, 63806392.

(78) Bayer, B. C.; Baehtz, C.; Kidambi, P. R.; Weatherup, R. S.; Mangler, C.; Kotakoski, J.; Goddard, C. J. L.; Caneva, S.; CabreroVilatela, A.; Meyer, J. C.; et al. Nitrogen Controlled Iron Catalyst Phase during Carbon Nanotube Growth. Appl. Phys. Lett. 2014, 105, 143111.

(79) Caneva, S.; Weatherup, R. S.; Bayer, B. C.; Brennan, B.; Spencer, S. J.; Mingard, K.; Cabrero-Vilatela, A.; Baehtz, C.; Pollard, A. J.; Hofmann, S. Nucleation Control for Large, Single Crystalline Domains of Monolayer Hexagonal Boron Nitride via Si-Doped Fe Catalysts. Nano Lett. 2015, 15, 1867-1875.

(80) Natesan, K.; Kassner, T. Thermodynamics of Carbon in Nickel, Iron-Nickel and Iron-Chromium-Nickel Alloys. Metall. Trans. A 1973, 4, 2557-2566.

(81) Adelhelm, C.; Balden, M.; Rinke, M.; Stueber, M. Influence of Doping (Ti, V, Zr, W) and Annealing on the sp2 Carbon Structure of Amorphous Carbon Films. J. Appl. Phys. 2009, 105, 033522.

(82) Bock, M. C. D.; Denk, R.; Wirth, C. T.; GoldbergOppenheimer, P.; Hofmann, S.; Baumberg, J. J. Optical Feedback Mechanisms in Laser Induced Growth of Carbon Nanotube Forests. Appl. Phys. Lett. 2012, 100, 013112.

(83) Michaelis, F. B.; Weatherup, R. S.; Bayer, B. C.; Bock, M. C.; Sugime, H.; Caneva, S.; Robertson, J.; Baumberg, J. J.; Hofmann, S. Co-Catalytic Absorption Layers for Controlled Laser-Induced Chemical Vapor Deposition of Carbon Nanotubes. ACS Appl. Mater. Interfaces 2014, 6, 4025-4032.

(84) Pustovalov, V. K. Theoretical Study of Heating of Spherical Nanoparticle in Media by Short Laser Pulses. Chem. Phys. 2005, 308, 103-108.

(85) Bock, M. Optical Growth of Carbon Nanotubes. Ph.D. Thesis, University of Cambridge, Cambridge, U.K., 2012.

(86) Bayer, B. C.; Fouquet, M.; Blume, R.; Wirth, C. T.; Weatherup, R. S.; Ogata, K.; Knop-Gericke, A.; Schlögl, R.; Hofmann, S.; Robertson, J. Co-Catalytic Solid-State Reduction Applied to Carbon Nanotube Growth. J. Phys. Chem. C 2012, 116, 1107-1113.

(87) Bayer, B. C.; Castellarin-Cudia, C.; Blume, R.; Steiner, S. A.; Ducati, C.; Chu, D.; Goldoni, A.; Knop-Gericke, A.; Schlögl, R.; Cepek, C.; et al. Tantalum-Oxide Catalysed Chemical Vapour Deposition of Single- and Multi-Walled Carbon Nanotubes. RSC Adv. 2013, 3, 4086-4092.

(88) Weatherup, R. S.; Bayer, B. C.; Blume, R.; Ducati, C.; Baehtz, C.; Schlögl, R.; Hofmann, S. In Situ Characterization of Alloy Catalysts for Low-Temperature Graphene Growth. Nano Lett. 2011, 11, 41544160 .

(89) Blume, R.; Rosenthal, D.; Tessonnier, J.-P.; Li, H.; KnopGericke, A.; Schlögl, R. Characterizing Graphitic Carbon with X-Ray Photoelectron Spectroscopy: A Step-by-Step Approach. ChemCatChem 2015, 7, 2871-2881.

(90) Goto, Y.; Taniguchi, K.; Omata, T.; Otsuka-Yao-Matsuo, S.; Ohashi, N.; Ueda, S.; Yoshikawa, H.; Yamashita, Y.; Oohashi, H.; Kobayashi, K. Formation of Ni3C Nanocrystals by Thermolysis of Nickel Acetylacetonate in Oleylamine: Characterization Using Hard XRay Photoelectron Spectroscopy. Chem. Mater. 2008, 20, 4156-4160.

(91) Patera, L. L.; Africh, C.; Weatherup, R. S.; Blume, R.; Bhardwaj, S.; Castellarin-Cudia, C.; Knop-Gericke, A.; Schloegl, R.; Comelli, G.;
Hofmann, S.; et al. In Situ Observations of the Atomistic Mechanisms of Ni Catalyzed Low Temperature Graphene Growth. ACS Nano 2013, 7, 7901-7912.

(92) Gelius, U.; Heden, P.; Hedman, J.; Lindberg, B.; Manne, R.; Nordberg, R.; Nordling, C.; Siegbahn, K. Molecular Spectroscopy by Means of ESCA III. Carbon Compounds. Phys. Scr. 1970, 2, 70.

(93) Kidambi, P. R.; Bayer, B. C.; Blume, R.; Wang, Z.-J.; Baehtz, C.; Weatherup, R. S.; Willinger, M.-G.; Schloegl, R.; Hofmann, S. Observing Graphene Grow: Catalyst-Graphene Interactions during Scalable Graphene Growth on Polycrystalline Copper. Nano Lett. 2013, 13, 4769-4778.

(94) Oswald, S.; Brückner, W. XPS Depth Profile Analysis of Nonstoichiometric NiO Films. Surf. Interface Anal. 2004, 36, 17-22.

(95) Weatherup, R. S.; D’Arsié, L.; Cabrero-Vilatela, A.; Caneva, S.; Blume, R.; Robertson, J.; Schloegl, R.; Hofmann, S. Long-Term Passivation of Strongly Interacting Metals with Single-Layer Graphene. J. Am. Chem. Soc. 2015, 137, 14358-14366.

(96) Blume, R.; Kidambi, P. R.; Bayer, B. C.; Weatherup, R. S.; Wang, Z.-J.; Weinberg, G.; Willinger, M.-G.; Greiner, M.; Hofmann, S.; Knop-Gericke, A.; et al. The Influence of Intercalated Oxygen on the Properties of Graphene on Polycrystalline $\mathrm{Cu}$ under Various Environmental Conditions. Phys. Chem. Chem. Phys. 2014, 16, 25989-26003.

(97) Petrov, I.; Barna, P.; Hultman, L.; Greene, J. Microstructural Evolution during Film Growth. J. Vac. Sci. Technol., A 2003, 21, S117S128.

(98) Schaefer, Z. L.; Gross, M. L.; Hickner, M. A.; Schaak, R. E. Uniform Hollow Carbon Shells: Nanostructured Graphitic Supports for Improved Oxygen-Reduction Catalysis. Angew. Chem. 2010, 122, 7199-7202.

(99) Yue, L.; Sabiryanov, R.; Kirkpatrick, E.; Leslie-Pelecky, D. L. Magnetic Properties of Disordered Ni 3 C. Phys. Rev. B: Condens. Matter Mater. Phys. 2000, 62, 8969.

(100) Hofer, L.; Cohn, E.; Peebles, W. The Isothermal Decomposition of Nickel Carbide. J. Phys. Colloid Chem. 1950, 54, 11611169.

(101) Nagakura, S. Study of Metallic Carbides by Electron Diffraction Part I. Formation and Decomposition of Nickel Carbide. J. Phys. Soc. Jpn. 1957, 12, 482-494.

(102) Leng, Y.; Xie, L.; Liao, F.; Zheng, J.; Li, X. Kinetic and Thermodynamics Studies on the Decompositions of $\mathrm{Ni} 3 \mathrm{C}$ in Different Atmospheres. Thermochim. Acta 2008, 473, 14-18.

(103) Sinharoy, S.; Smith, M.; Levenson, L. Thermal Decomposition of Nickel Carbide Thin Films. Surf. Sci. 1978, 72, 710-718.

(104) Ruitenberg, G.; Woldt, E.; Petford-Long, A. Comparing the Johnson-Mehl-Avrami-Kolmogorov Equations for Isothermal and Linear Heating Conditions. Thermochim. Acta 2001, 378, 97-105.

(105) Callister, W. D.; Rethwisch, D. G. Materials Science and Engineering: An Introduction; Wiley: New York, 2007; Vol. 7.

(106) Kling, J.; Hansen, T. W.; Wagner, J. B. Quantifying the Growth of Individual Graphene Layers by in Situ Environmental Transmission Electron Microscopy. Carbon 2016, 99, 261-266.

(107) Ramirez, A.; Itoh, T.; Sinclair, R. Crystallization of Amorphous Carbon Thin Films in the Presence of Magnetic Media. J. Appl. Phys. 1999, 85, 1508-1513.

(108) Nast, O.; Puzzer, T.; Koschier, L. M.; Sproul, A. B.; Wenham, S. R. Aluminum-Induced Crystallization of Amorphous Silicon on Glass Substrates above and below the Eutectic Temperature. Appl. Phys. Lett. 1998, 73, 3214-3216.

(109) Herd, S.; Chaudhari, P.; Brodsky, M. Metal Contact Induced Crystallization in Films of Amorphous Silicon and Germanium. J. NonCryst. Solids 1972, 7, 309-327.

(110) Weatherup, R. S.; Bayer, B. C.; Blume, R.; Baehtz, C.; Kidambi, P. R.; Fouquet, M.; Wirth, C. T.; Schlögl, R.; Hofmann, S. On the Mechanisms of Ni-Catalysed Graphene Chemical Vapour Deposition. ChemPhysChem 2012, 13, 2544-2549.

(111) Weatherup, R. S.; Dlubak, B.; Hofmann, S. Kinetic Control of Catalytic CVD for High-Quality Graphene at Low Temperatures. ACS Nano 2012, 6, 9996-10003. 
(112) Trimm, D. Catalysts for the Control of Coking during Steam Reforming. Catal. Today 1999, 49, 3-10.

(113) Gonzalez, I.; De Jesus, J. C.; Cañizales, E.; Delgado, B.; Urbina, C. Comparison of the Surface State of Ni Nanoparticles Used for Methane Catalytic Decomposition. J. Phys. Chem. C 2012, 116, 21577-21587.

(114) Lander, J.; Kern, H.; Beach, A. Solubility and Diffusion Coefficient of Carbon in Nickel: Reaction Rates of Nickel-Carbon Alloys with Barium Oxide. J. Appl. Phys. 1952, 23, 1305-1309.

(115) Weatherup, R. S.; Amara, H.; Blume, R.; Dlubak, B.; Bayer, B. C.; Diarra, M.; Bahri, M.; Cabrero-Vilatela, A.; Caneva, S.; Kidambi, P. $\mathrm{R}$; et al. Interdependency of Subsurface Carbon Distribution and Graphene-Catalyst Interaction. J. Am. Chem. Soc. 2014, 136, 1369813708 . 